\section{Concentração e Competição no Mercado de Crédito Doméstico}

\author{
Concentration and Competition in the Domestic Credit Market
}

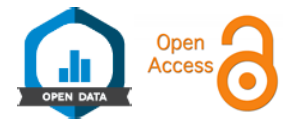

Monique de Abreu Azevedo', $2 \odot$
Ivan Ricardo Gartner

\section{RESUMO}

Contexto: o mercado financeiro tem vivenciado acentuadas reestruturações e concentrações nas últimas décadas. À medida que os bancos expandem o escopo de suas atividades, levantam preocupações quanto ao impacto sobre a competitividade do setor. Se as características da indústria financeira, que colaboram para tornar o setor mais concentrado, podem torná-la menos competitiva, implica avaliar a relação entre concentração e concorrência. Objetivo: o objetivo geral deste estudo consiste em promover diagnóstico da organização do mercado de crédito nacional mediante cálculo e análise de indicadores de concentração e de competição, entre 2000 e 2019. Métodos: para mensurar a concentração, são utilizados os índices de Herfindahl-Hirschman e a Razão de Concentração dos Cinco Maiores. O grau de competição é estimado via modelo econométrico de Lerner aplicado a dados dispostos em um painel com informações contábeis-financeiras de instituições financeiras. Resultados: os resultados sugerem que embora a concentração tenha se elevado no recorte temporal considerado, a competitividade não se deteriorou, reforçando o argumento de referências seminais de que concentração não necessariamente prejudica competição. Conclusão: diante de ausência de consenso acadêmico, este trabalho elucida a relação entre concentração e competitividade. Ainda, ganha relevância ao apontar o papel da regulação e das cooperativas de crédito no aumento da concorrência recente. $\mathrm{O}$ trabalho torna-se, assim, passível de apoiar políticas capazes de promover a contestabilidade, como iniciativas que flexibilizem restrições à entrada de instituições não bancárias e de empresas de tecnologia financeira.

Palavras-chave: concentração; competição; crédito; bancos; cooperativas de crédito

Classificação JEL: E5, D4, P1.

' Universidade de Brasília, Programa de Pós-Graduação em Administração, Brasília, DF, Brasil.

${ }^{2}$ Banco Central do Brasil, Brasília, DF, Brasil.

Como citar: Azevedo, M. de A., \& Gartner, I. R. (2020). Concentration and competition in the domestic credit market. Revista de Administração Contemporânea, 24(5), 380-399. https://doi.org/10.1590/1982-7849rac2020190347

\section{ABSTRACT}

Context: the financial market has experienced sharp restructuring and mergers in recent decades. As banks expand the scope of their activities, they raise concerns about the impact on the sector's competitiveness. If the characteristics of the financial industry, which contribute to make the sector more concentrated, can make it less competitive, it implies assessing the relationship between concentration and competition. Objective: the general objective of this study is to promote diagnosis of the organization of the national credit market by calculating and analyzing concentration and competition indicators, between 2000 and 2019. Methods: to measure concentration, the Herfindahl-Hirschman and the Five Major Concentration Ratio indexes are used. The degree of competition is estimated via Lerner's econometric model applied to data displayed on a panel with accounting and financial information from financial institutions. Results: the results suggest that although the concentration has increased in the time frame considered, competitiveness has not deteriorated, reinforcing the argument of seminal references that concentration does not necessarily harm competition. Conclusion: in the absence of academic consensus, this work elucidates the relationship between concentration and competitiveness. Still, it gains relevance by pointing out the role of regulation and credit unions in increasing recent competition. The work thus becomes capable of supporting policies that promote contestability, such as initiatives that relax restrictions on the entry of non-banking institutions and financial technology companies.

Keywords: concentration; competition; credit; banks; credit unions.

Editor-chefe: Wesley Mendes-Da-Silva (Fundação Getulio Vargas, EAESP, Brasil) Pareceristas: Flávia Vital Januzzi (Universidade Federal de Juiz de Fora, Brasil) Luiz Eduardo Gaio (Universidade Estadual de Campinas, Brasil) (b)

Recebido em: 21/10/2019 Última versão recebida em: 02/03/2020 Aceite em: 24/03/2020

\begin{tabular}{|c|c|c|c|c|c|c|c|c|c|}
\hline & 1 & 2 & 3 & 4 & 5 & 6 & 7 & 8 & 9 \\
\hline $1^{a}$ rodada & (x) & (x) & (x) & (x) & (x) & (x) & $\stackrel{\infty}{6}$ & 9 & (x) \\
\hline $2^{a}$ rodada & 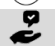 & 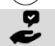 & & & & & & & \\
\hline
\end{tabular}




\section{INTRODUÇÃO}

O mercado financeiro mundial tem vivenciado acentuadas reestruturações e concentrações nas últimas décadas (Hankir, Rauch, \& Umber, 2011). As fusões bancárias podem ser explicadas, segundo os autores supra, pela busca de poder de mercado, por ondas de reorganizações societárias, por sinergias operacionais e financeiras, para impedir que competidores comprem alvos preferenciais e por problemas financeiros. Sobretudo após a crise econômica global de 2008, autoridades monetárias estimularam a concentração de instituições financeiras (IF) o que contribuiu para a maior eficiência da regulação e da supervisão da indústria (Montes, 2014). Fusões e aquisições se apresentam como alternativas privadas para instituições frágeis permanecerem em funcionamento, sem gerar gasto público e em razão de potencial apropriação de benefícios tributários por parte da adquirente (Bulow \& Shoven, 1978).

À medida que as IF expandiam suas atividades, através das fronteiras nacionais e da oferta de novos serviços, levantaram preocupações acerca da competitividade, ou seja, da menor oferta de crédito a preços maiores quando comparado ao ambiente de competição perfeita. Se as características do setor financeiro, que colaboram para tornar a indústria mais concentrada, podem reduzir a competição, implica estimar e analisar a relação entre concentração e a concorrência. Nesse aspecto, importa ressaltar que a literatura predominantemente mostra que a concentração não é uma medida apropriada para a competição (Bikker, Shaffer, \& Spierdijk, 2009).

A percepção dos agentes econômicos acerca dos efeitos da concentração sobre o custo da intermediação financeira e, ainda, sobre a estabilidade tem incitado estudos científicos. A teoria Estrutura-Conduta-Desempenho (VanHoose, 1985) sugere que a concentração, caracterizada pela presença de poucas IF de grande porte eleva a lucratividade mediante cobrança de juros maiores nos empréstimos e pagamento de juros menores aos depositantes, reduzindo o bem-estar social. Resultados empíricos apresentados por Gilbert (1984) sugerem que o aumento na concentração provocou elevação dos juros médios dos empréstimos e queda dos juros dos depósitos no mercado bancário norte-americano.

$\mathrm{Na}$ perspectiva da Estrutura-Eficiente (VanHoose, 1985), em contraste, os benefícios provenientes de economias de escala e de escopo reduzem as taxas de juros dos empréstimos e elevam as dos depósitos pois a lucratividade advém de ganhos de eficiência. Estudos mais recentes têm respaldado a existência de uma relação inversa entre concentração e juros do crédito (Fungácová, Shamshur, \& Weill, 2017). Ainda, têm indicado a importância de diferenciar competição e concentração. Claessens e Laeven (2004) concluíram que mercados financeiros desenvolvidos, com menor barreira à entrada a novas organizações e a serviços provenientes de inovações financeiras, podem ser competitivos ainda que concentrados.

Tampouco existe consenso entre concentração e estabilidade, bem como entre competição e estabilidade. Vries (2005) concluiu que concentrar o risco em instituições individuais eleva a frequência de falhas isoladas. Matutes e Vives (1996; 2000) argumentam que um mercado livre contribui para a estabilidade. Maghyereh e Awartani (2014), por seu turno, apontaram que a concorrência e a diversificação não contribuem para a saúde dos bancos.

Segundo VanHoose (2010), as teorias concernentes a estruturas intermediárias de mercado, ou seja, entre a competição perfeita e o monopólio puro, são as mais adequadas para explicar o comportamento da indústria bancária. Há, ainda, a competição monopolística (Chamberlin, 1962) em que o monopólio decorre do grau de diferenciação dos produtos ofertados.

Diante do exposto, a estimativa e a avaliação da competitividade do mercado de crédito nacional conduzidos neste artigo preenchem uma lacuna científica, em razão do recorte temporal, dos Tipos de Consolidado Bancário (TCB) considerados e da metodologia aplicada. A literatura teóricoempírica que avalia concorrência no setor é escassa, sobretudo no tocante aos países emergentes como o Brasil, em razão da falta de dados e da complexidade do cálculo (Bikker \& Haff, 2002; Turk-Ariss, 2010).

Além disso, esta pesquisa ganha relevância ao elucidar a relação entre concentração e concorrência. O nexo entre concentração e competitividade não é matéria pacificada, tanto sob a perspectiva teórica quanto empírica. À frente de tal discussão, ainda traz à baila a importância da regulação, como sugere a literatura (Akin, Aysan, Borici, \& Yildiran, 2013; Claessens \& Laeven, 2004), e da atuação de instituições não bancárias sobre o aumento da competição recente no mercado de crédito doméstico.

Importa ressaltar que o setor financeiro vivencia uma transformação com a entrada recente das empresas de tecnologia financeira, que inclui bancos digitais, fintechs e grandes companhias. As inovações tecnológicas aumentam o potencial de acirrar a concorrência no mercado de crédito. Em meio a essas mudanças e dos debates acadêmicos revelados, este artigo se propõe a avaliar o nível de concentração e de competição, suas causas e 
potenciais consequências, tornando-se relevante tema de pesquisa.

Nesse contexto, este estudo tem como objetivo geral avaliar a organização do mercado de crédito nacional, mediante cálculo e análise de indicadores que refletem concentração e concorrência entre o primeiro trimestre de 2000 e o primeiro trimestre de 2019. O Índice de Herfindahl-Hirschman (IHH) e a Razão de Concentração dos Cinco Maiores (RC5), propostos pela literatura e por autoridades reguladoras, conforme VanHoose (2010) e Banco Central do Brasil (BACEN) (2018), são utilizados para mensurar a concentração. O grau de competição é estimado via Indicador de Lerner. Com os resultados do IHH, da RC5 e do Índice de Lerner, é possível avaliar a relação entre concentração e competição.

Como objetivos específicos, essa pesquisa compara a concorrência entre os diferentes TCB (b1, b2, b3S e n1) que compõem o setor bancário e o não bancário nacional, com o intuito de identificar qual o grupo de IF contribui para a competição. Ainda, avalia-se a competitividade por segmentação (S1, S2, S3, S4 e S5), assim classificadas pela Resolução $\mathrm{n}^{\mathrm{o}} 4.553 / 2017$ (Conselho Monetário Nacional [CMN], 2017) de acordo com o porte, a atividade internacional e o perfil de risco da organização. Espera-se que a segmentação, implementada pela regulação prudencial proporcional de requerimento de capital, tenha contribuído para a melhora da concorrência.

Cabe enfatizar que a literatura sobre competitividade bancária inovou com o desenvolvimento do método de Lerner (Delis \& Tsionas, 2009; Lerner, 1934), utilizado neste artigo. Considerado preferível a proxies como a Estatística- $\mathrm{H}$ (Turk-Ariss, 2010), o Indicador de Lerner estima o poder de mercado de uma empresa pela diferença entre o preço praticado pela organização e o seu custo marginal, também conhecido como margem ou mark-up. O método alinha-se ao conceito de poder de mercado dado pela capacidade da instituição financeira cobrar juros no crédito acima do custo marginal (VanHoose, 2010).

A primeira hipótese do presente estudo é a de que o aumento da concentração na indústria financeira nacional atuante no crédito não implica redução da competitividade, no recorte temporal considerado. Avalia-se, nesse aspecto, potenciais explicações para a trajetória do Indicador Lerner, com amparo na literatura científica. Assim, como segunda hipótese, espera-se que aspectos regulatórios tenham contribuído para a melhora recente da concorrência. A terceira hipótese consiste em buscar evidências de que a competitividade entre os diversos grupos de IF que compõem o mercado nacional de crédito é heterogênea, e, assim, as margens aplicadas pelos bancos são maiores que às praticadas pelas cooperativas de crédito.

A próxima seção apresenta o referencial teórico acerca da organização industrial bancária. Na seção subsequente, há uma descrição do método teórico utilizado para estimar os indicadores de concentração e de competição. Em seguida, a seção 4 apresenta a aplicação do método, desde a seleção da amostra, a definição das proxies até as técnicas empregadas para estimação da regressão do custo total e para a análise dos resultados. A seção 5 dedica-se à análise do modelo econométrico e à apresentação dos resultados dos índices, contendo, ainda, discussões sobre possíveis causas. Por fim, são tecidas as conclusões, limitações, implicações práticas e sugestões para estudos futuros.

\section{REFERENCIAL TEÓRICO}

A análise de política econômica da organização industrial bancária tem sido guiada pela StructureConduct-Performance (SCP) e pela EfficientStructure Theory (ES), segundo VanHoose (2010). Na SCP, a maior concentração eleva a lucratividade mediante cobrança de juros maiores nos contratos de créditos e pagamento de juros menores aos depositantes, reduzindo o bem-estar da população. Na ES, o aumento dos lucros pode ser explicado pela eficiência, advinda de ganhos de escala e de escopo. Nesse contexto, não há uma relação positiva clara entre concentração e desempenho. Aspectos relacionados a contestabilidade do mercado têm se mostrado significantes para explicar a competição (Claessens \& Laeven, 2004).

Vale destacar, ainda, a New Empirical Organization (NEIO) que mede a competição por meio da estimativa de indicadores, sem suposições exante acerca da estrutura ou da conduta de mercado. Nessa abordagem, destacam-se o método PanzarRosse (1987) e o de Lerner (1934) que podem ser formalmente derivados de condições de equilíbrio supondo maximização dos lucros (Bikker, Shaffer e Spierdijk, 2009).

Evidências empíricas dão suporte à SCP, à ES e à NEIO. Sob à SCP, resultados empíricos apresentados por Gilbert (1984) sugerem que 10\% de aumento na concentração elevou os juros dos empréstimos entre 0,1 e 11 pontos bases e reduziu os dos depósitos dos bancos nos EUA entre 0,1 e 18. Segundo Shaffer e Srinivasan (2002), a concentração contribuiu para as elevadas taxas dos empréstimos praticadas no mercado bancário estadunidense. A perspectiva da SCP baseia-se no modelo banco dominante, ou seja, na suposição de que grandes bancos detêm vantagens sobre rivais menores no que tange aos 
custos e, portanto, apresentam um comportamento anticompetitivo no tocante aos preços.

Sob a égide da ES, os benefícios provenientes de economias de escala e de escopo reduzem as taxas de juros dos empréstimos e elevam as dos depósitos. Nessa abordagem, os juros cobrados pelos bancos maiores, que arcam com menores custos unitários, restringem as taxas praticadas por rivais menores, resultando em taxas de empréstimo médias mais baixas e de depósito mais altas. Lucros mais elevados das grandes IF devem-se à eficiência, não às condutas predatórias destinadas a dificultar a entrada de novas instituições.

Estudos recentes têm respaldado a existência de uma relação inversa entre concentração e juros do crédito (Fungácová, Shamshur, \& Weill, 2017; Silva, 2014; Tonooka \& Koyama, 2003) em razão de fatores como regulação, rigidez informacional e educação financeira limitada. Ao aplicar o método Panzar-Rosse, Claessens e Laeven (2004) não encontraram evidências de que competição se relaciona com concentração nos mais de 4.000 bancos em 50 países. Concluindo que mercados financeiros desenvolvidos mais contestáveis a novas organizações e a serviços tendem a serem competitivos mesmo que concentrados.

No que concerne ao risco, Berger, Leora e TurkAriss (2008), ao examinar mais de 8.000 bancos em 23 países entre 1999 e 2005, encontrou um menor grau de exposição ao risco geral em bancos que possuíam maior poder de mercado. Já Vries (2005), que propôs um modelo teórico de risco sistêmico advindo das interconexões do mercado de depósito, concluiu que concentrar o risco em instituições individuais eleva a frequência de falhas isoladas. Assim, sugere a segregação do risco em múltiplas instituições.

Matutes e Vives (1996; 2000) desenvolveram modelos que associam o colapso bancário e a competição imperfeita no mercado de depósito, em consequência, uma maior competitividade seria salutar. Allen e Gale (2004) argumentaram que a competição perfeita no mercado interbancário reduz a estabilidade. Maghyereh e Awartani (2014) apontaram que a concorrência e a diversificação não contribuem para a saúde dos bancos.

A atividade bancária viabiliza a intermediação financeira entre poupadores e investidores, contudo, traz riscos cuja origem está na captação de depósitos resgatáveis a qualquer tempo para oferecer crédito. Aspectos relacionados à competição, como a eficiência, embora socialmente desejáveis, podem criar riscos aos bancos individualmente e a nível sistêmico. Se a regulamentação que cria barreiras à entrada, tornando o setor mais concentrado e, possivelmente, menos competitivo, reduz o risco de insolvência, é uma pergunta que implica decifrar, primeiramente, os níveis de concentração e de competição (VanHoose, 2010).

As estruturas intermediárias de mercado são as mais adequadas para explicar a indústria bancária (VanHoose, 1985). A abordagem de Cournot, que assume a existência de alguns concorrentes oferecendo produtos homogêneos (Dasgupta \& Stiglitz, 1981), pode ser usada para examinar esse mercado. Trata-se de modelo de oligopólio em que a oferta de crédito e de depósito depende da estimativa da quantidade produzida pelos concorrentes (Pindyck \& Rubinfeld, 2010). No oligopólio, há barreiras à entrada a novos participantes. Outra abordagem consiste no modelo de competição monopolística (Chamberlin, 1962) em que há concorrentes e não há restrições para novos entrantes. O poder do monopólio decorre do grau de diferenciação dos produtos ofertados.

Nesses ambientes intermediários de mercado, as taxas de juros dos empréstimos tendem a ser maiores e as dos depósitos menores, quando comparadas aos praticados em competição perfeita. Em 2015, Tabak, Gomes e Medeiros (2015) haviam sinalizado que a concentração nas carteiras de crédito aumenta a eficiência de monitoramento uma vez que facilita a recuperação de empréstimos tornando o banco menos suscetível ao risco.

O Índice de Herfindahl-Hirschman (IHH) e a Razão de Concentração dos Cinco (RC5) são propostos pela academia e por autoridades monetárias para medir a concentração do sistema financeiro (BACEN, 2017; 2018; VanHoose, 2010). Quanto ao nível de competição, recomenda-se a estimativa dos indicadores de Lerner e de Boone (BACEN, 2017; 2018; Boone, 2008; Lerner, 1934).

O Índice de Lerner (Berger, Klapper, \& TurkAriss, 2009; Lerner, 1934) mede a capacidade de um banco maximizador de lucro exercer poder de mercado impondo juros de empréstimos elevados em relação ao seu custo, sem perda expressiva de clientes. Tal capacidade depende da elasticidade da demanda por crédito em relação aos juros. Em ambientes competitivos, espera-se uma elevada elasticidade de juros da demanda por crédito e, portanto, dificuldades em elevar as taxas. Bancos com poder de mercado, por outro lado, tendem a estabelecer suas taxas aplicando um mark-up ótimo sobre seu custo marginal em emprestar.

Assim quanto maior o poder de mercado da instituição financeira, maior a margem de lucro auferida e maior o valor do Indicador de Lerner. Por exemplo, suponha que a taxa de encargos financeiros cobrada do tomador de crédito seja de $20 \%$ ao ano e o custo de conceder uma unidade adicional de crédito, conhecido como custo marginal, seja de 
$10 \%$ ao ano. Nessas condições, o mark-up sobre o custo marginal será de 10 pontos percentuais e o índice de Lerner será 0,50 ou $50 \%$ do preço do crédito, advindo do quociente entre 10 e 20 .

Assim, o Indicador de Lerner captura o quanto as taxas cobradas excedem o custo marginal, em termos relativos, ou seja, em percentual do preço. Idealmente o Indicador deve levar em consideração as taxas praticadas nas operações de empréstimos e nos depósitos separadamente o que muitas vezes não é viável em razão de obstáculos em relação aos dados (Turk-Ariss, 2010). Diante disso, o Indicador tem sido construído na literatura de modo a abranger a totalidade da atividade da IF (Angelini \& Ceterolli, 2003), o chamado Lerner convencional.

O índice de Boone (Boone, 2008) se propõe a medir a sensibilidade da participação da IF no mercado em relação a variações no seu custo marginal. Em um ambiente competitivo, aumentos no custo marginal tendem a provocar elevações nas taxas cobradas nos empréstimos, comparativamente às demais instituições, com consequente redução da sua participação no mercado. Quanto mais negativo o índice de Boone, maior o nível de competição no setor. Os indicadores de Lerner e de Boone são considerados métricas complementares para mensurar o nível de competição (BACEN, 2017).

\section{O MODELO TEÓRICO}

Esta seção descreve o método teórico utilizado para mensurar os indicadores que refletem a concentração e a competitividade nos segmentos bancário e não bancário doméstico para os empréstimos concedidos no Brasil. No tocante à concentração, esta pesquisa calcula o Índice de Herfindahl-Hirschman (IHH) e a Razão dos Cinco Maiores (RC5). Ambos medem participações de mercado, sem implicações, a priori, acerca do comportamento competitivo das instituições.

O IHH é obtido pelo somatório do quadrado da participação na forma decimal de cada IF no mercado de crédito, conforme mostra a Equação (1). Seus resultados assumem valores entre 0 (ausência de concentração) e 1 (totalmente concentrado), sendo que estimativas entre 0,1000 e 0,1800 representam moderada e, acima de 0,1800, elevada concentração (BACEN, 2017, 2018, VanHoose, 1985).

$$
\mathrm{IHH}=\sum_{i=1}^{n}\left(\frac{\text { Estoque de Operações de Crédito do banco } i}{\text { Total do Estoque de Crédito do sistema }}\right)^{2}
$$

A RC5, calculada de acordo com a Equação (2), consiste na participação das 5 (cinco) maiores instituições no total dos empréstimos oferecido pelo setor bancário e não bancário. Os resultados da RC5, assim como do IHH, também variam entre 0 (ausência de concentração) a 1 (concentração máxima).

$R C 5=\sum_{i=1}^{5}\left(\frac{\text { Estoque de Operações de Crédito do banco } i}{\text { Total do Estoque de Crédito do sistema }}\right)$

No que cinge à competição, o Indicador de Lerner estima o poder de mercado pela diferença entre o preço cobrado no produto crédito e o custo marginal da IF, em percentagem do preço, como mostra a Equação (3) (BACEN, 2017; 2018; Turk-Ariss, 2010; VanHoose, 1985). Seus resultados se dão em dimensões contínuas que variam desde a competição plena $\left(\mathrm{L}_{\mathrm{it}}=0\right)$ à ausência de competição $\left(\mathrm{L}_{\mathrm{it}}=1\right)$. Se a IF busca maximizar lucro, o Índice apresenta resultado não negativo. Contudo, se o banco tiver outros objetivos, seu Lerner pode ser negativo, mesmo que aufira lucro.

$$
L_{i t}=\left(\frac{P_{i t}-\operatorname{Cmarg}_{i t}}{P_{i t}}\right)
$$

Onde:

$L_{i t}$ : indicador de Lerner da $I F_{i}$ no período $t$;

Cmarg $_{i t}$ : custo marginal da $I F_{i}$ em $t$ (obtido a partir da derivada parcial da função custo total dada pela Equação 5); e

$P_{i t}$ : preço do produto de crédito da $I F_{i}$ em $t$, estimado pela razão entre suas receitas de operações de crédito e o total do estoque de crédito.

A mensuração da competitividade requer a estimativa do custo marginal, que corresponde ao incremento do custo total em ofertar uma unidade adicional de empréstimo. Silva (2014) ressalta que somente agentes internos da organização conhecem os custos marginais. Diante disso, a literatura científica recomenda estimar a função transcendental logarítmica (translog) do custo total, dado pela Equação (4) (Silva, 2014; Tabak, Gomes, \& Medeiros, 2015; Turk-Ariss, 2010). A translog consiste em forma funcional geral introduzida por Christensen, Jorgenson e Lau (1973) considerada flexível, com termos lineares e quadráticos, podendo ser usada para testar hipóteses da teoria da firma. Usualmente interpretada como uma aproximação por uma série de expansão de Taylor de segunda ordem, permite trabalhar com valores discricionários para a elasticidade de substituição entre pares de insumos. 
$\ln \left(\frac{T C_{i t}}{w_{2 i t}}\right)=\lambda_{0}+\Sigma_{j} \lambda_{j} \ln \left(y_{j i t}\right)+\Sigma_{j} \Sigma_{k} \lambda_{j k} \ln \left(y_{j i t}\right) \ln \left(y_{k i t}\right)+\beta_{1} \ln \left(\frac{w_{1 i t}}{w_{2 i t}}\right)+\frac{1}{2} \beta_{11} \ln \left(\frac{w_{1 i t}}{w_{2 i t}}\right)^{2}+\Sigma_{j} \theta_{j} \ln \left(y_{j i t}\right) \ln \left(\frac{w_{1 i t}}{w_{2 i t}}\right)+$ $\Sigma_{t} \tau_{t} D_{t}+\Sigma_{t} \Gamma_{t} D_{t} y_{1 i t}+\varepsilon_{i t}$

Onde:

$T C_{i t}:$ custo total da IF, no período $t$

$w_{1}$ : custo operacional;

$w_{2}$ : custo de captação;

$y_{j i t}$ : vetor de produtos financeiros envolvendo crédito ( $\left.j=1\right)$, ativos líquidos ( $\left.j=2\right)$ e outros ativos $(j=3)$;

$D_{i t}:$ vetor de variáveis dummies da $I F_{i} ; e$

$\varepsilon_{i t}=v_{i t}+u_{i}$ : termo de erro, onde as perturbações $v_{i t}$ são normal e independentes distribuídas; $e$

$u_{i t} \sim N(0, \sigma)$ e var $\left(u_{i}\right)=\sigma^{2}$.

No campo da teoria da firma, a função custo é considerada uma função de produção, que relaciona produtos aos respectivos fatores de produção utilizados no processo produtivo. Estimados os coeficientes da função de produção da Equação (4), obtidas via modelo econométrico de regressão múltipla, é possível mensurar o custo marginal das operações de crédito para cada IF em cada período, conforme Equação (5).

$$
\operatorname{Cmag}_{1 i t}=\left(\frac{\frac{T C_{i t}}{w_{2 i t}}}{y_{1 i t}}\right)\left[\lambda_{1}+2 \lambda_{11} \ln \left(y_{1 i t}\right)+\lambda_{12} \ln \left(y_{2 i t}\right)+\lambda_{13} \ln \left(y_{3 i t}\right)+\theta_{1} \ln \left(\frac{w_{1 i t}}{w_{2 i t}}\right)\right]+\Sigma_{t} \tau_{t} D_{t}
$$

\section{APLICAÇÃO DO MÉTODO}

\section{Definição da amostra e fonte de dados}

O IHH, a RC5 e o Índice de Lerner são mensurados nesta pesquisa na periodicidade trimestral, do primeiro trimestre de 2000 (I tri 2000) ao primeiro trimestre de 2019 (I tri 2019), incorporando, portanto, a última crise financeira mundial. A janela de tempo de aproximadamente 20 anos (77 trimestres) pode ser considerada suficiente para acomodar ciclos de alta e de baixa no mercado de ativos e na economia. Além disso, trata-se do maior período disponível para as informações contábeis publicadas no banco de dados do BACEN, o IF.data (https://www3.bcb. gov.br/ifdata/, recuperado em 30 de Julho, 2019), até o momento da submissão desse artigo.

Os índices de concentração e de competição contemplam as instituições financeiras isoladas entre o I tri 2000 e o I tri 2019 pertencentes ao segmento bancário, tipo b1 e b2, e não bancário, tipo n1 e b3S, doravante, sistema, conforme explicita a Tabela 1. As instituições dos tipos b1, b2, b3S e n1 correspondem a cerca de 93\% do mercado de crédito no final de 2018, conforme dados disponíveis do IF.data.

Tabela 1. Tipos de consolidado bancário.

\begin{tabular}{cc}
\hline Nomenclatura & Significado \\
\hline b1 & Banco comercial, banco múltiplo com carteira comercial ou caixa econômica \\
b2 & Banco múltiplo sem carteira comercial ou banco de investimento ou banco de câmbio \\
b3S & Cooperativa de crédito singulares \\
n1 & Não bancário de crédito \\
\hline
\end{tabular}

Nota. Elaboração dos autores. Fonte: Banco Central do Brasil. (2018). Relatório de economia bancária 2018. Retrieved from https://www.bcb.gov.br/content/ publicacoes/relatorioeconomiabancaria/reb_2018.pdf; e IF.data (disponível em https://www3.bcb.gov.br/ifdata/, recuperado em 12 de Junho, 2019).

O segmento bancário TCB b1 é representado, segundo a autoridade monetária (BACEN, 2018), pelos bancos comerciais, múltiplos com carteira comercial e caixas econômicas. Os bancos múltiplos sem carteira comercial e os de investimento compõem o segmento bancário tipo b2. As cooperativas de crédito singular e as instituições não bancárias de crédito são representadas por b3S e n1, respectivamente.

Dessa forma, foi possível formar um painel não balanceado com informações de 1.720 Instituições 
Individuais. Segundo a autoridade reguladora, essas organizações compreendem as instituições financeiras e demais instituições autorizadas a funcionar pelo Banco Central separadas por personalidade jurídica (CNPJ), em nível não consolidado. Nessa configuração, as participações societárias no Brasil e/ou no exterior e as agências no exterior são registradas como investimento por meio do método da equivalência patrimonial.

Vale ilustrar que as instituições não bancárias de crédito (n1) são representadas por organizações como sociedades de arrendamento mercantil, companhias hipotecárias e sociedade de crédito ao microempreendedor. As cooperativas de crédito singular (b3S) realizam diretamente o atendimento a clientes. Embora as cooperativas não visem lucro, buscam maximizar o benefício usufruído por seus cooperados e manter seus projetos em níveis sustentáveis, o que permite avaliar a sua competitividade por meio do Indicador de Lerner.

Os Relatórios de Economia Bancária do Banco Central (BACEN, 2017; 2018) consideram, na estimativa do Índice de Lerner, tanto as cooperativas de crédito quanto as instituições não bancárias de crédito. A estimativa por parte do BACEN não contempla os bancos de desenvolvimento. Os bancos de desenvolvimento, classificados como TCB b4, também não são considerados nesta pesquisa pois não visam lucro, tampouco maximizam benefícios de seus representantes. Essas instituições representavam $8,4 \%$ das operações de crédito líquidas de provisão no III tri 2018.

\section{Variáveis e proxies do estudo}

Para estimar os índices de concentração e de concorrência, fez-se uso de informações contábeis trimestrais das Instituições Financeiras Individuais participantes do sistema publicadas pelo BACEN no banco de dados IF.data. A seleção das proxies baseouse no Relatório de Economia Bancária (BACEN, 2017; 2018), em Ornelas, Silva e VanDoornik (2020), em Turk-Ariss (2010) e VanHoose (2010), conforme detalha a Tabela 2 .

Tabela 2. Variáveis, referências, proxies e fórmulas utilizadas para calcular o IHH, a RC5 e o Índice de Lerner.

\begin{tabular}{|c|c|c|}
\hline Variáveis & Referências das proxies & Fórmulas e proxies adotadas de acordo com o nome das rubricas contábeis do IF.data \\
\hline $\begin{array}{l}I H H: \text { Índice de } \\
\text { Herfindahl-Hirschman }\end{array}$ & $\begin{array}{l}\text { BACEN (2017) } \\
\text { BACEN (2018) } \\
\text { VanHoose (2010) }\end{array}$ & $I H H=\sum_{i=1}^{n}\left(\frac{\text { Estoque de Operações de Crédito do banco } i}{\text { Total do Estoque de Crédito do sistema }}\right)^{2} ; \quad I H H=\sum_{i=1}^{n}\left(\begin{array}{l}\text { Operações de Crédito Líquidas de Provisão }(d)+ \\
\frac{\text { Arrendamento Mercantil Líquido de Provisões }(e)}{\text { Total do Estoque de Crédito do sistema }}\end{array}\right)^{2}$ \\
\hline $\begin{array}{l}R C 5 \text { : Razão dos Cinco } \\
\text { Maiores }\end{array}$ & $\begin{array}{l}\text { BACEN (2017) } \\
\text { BACEN (2018) } \\
\text { VanHoose (2010) }\end{array}$ & $R C 5=\sum_{i=1}^{5}\left(\frac{\text { Estoque de Operações de Crédito do banco } i}{\text { Total do Estoque de Crédito do sistema }}\right) ; R C 5=\sum_{i=1}^{5}\left(\begin{array}{l}\text { Operações de Crédito Líquidas de Provisão }(d)+ \\
\frac{\text { Arrendamento Mercantil Líquido de Provisões }(e)}{\text { Total do Estoque de Crédito do sistema }}\end{array}\right)$ \\
\hline $\begin{array}{l}P_{i t}: \text { Preço do produto } \\
\text { crédito da IF } i \text { em } t\end{array}$ & $\begin{array}{l}\text { BCB (2017) } \\
\text { BCB (2018) } \\
\text { Ornelas et al. (2020) }\end{array}$ & 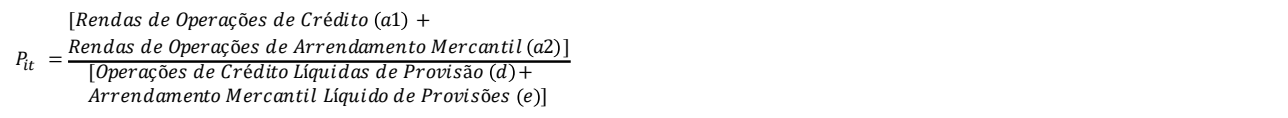 \\
\hline $\begin{array}{l}T C_{i t}: \text { Custo total da IF } \\
i \text { em } t\end{array}$ & $\begin{array}{l}\text { BCB (2017) } \\
\text { BCB }(2018) \\
\text { Ornelas et al. (2020) } \\
\text { Turk-Ariss (2010) }\end{array}$ & $\begin{array}{c}T C_{i t}= \\
{[\text { Despesas de Captação , por Empréstimos e Repasses }(b 2) \text { e }} \\
\text { de Operações de Arrendamento Mercantil }(b 3) \\
+ \text { Resultado de Provisão para Créditos de Difícil Liquidação }(b 5) \\
\text { Despesas Operacionais }\left(w_{1}\right)+\text { Despesas Tributárias }(d 5)+ \\
\text { Imposto de Rendae Contribuição Social }(h)]\end{array}$ \\
\hline $\begin{array}{l}w_{1 i t}: \text { Custo } \\
\text { operacional ou } \\
\text { despesas operacionais }\end{array}$ & $\begin{array}{l}\text { BCB (2017) } \\
\text { BCB (2018) } \\
\text { Ornelas et al. (2020) } \\
\text { Turk-Ariss (2010) }\end{array}$ & $w_{1}=\frac{\begin{array}{l}{[\text { Despesa de Pessoal }(d 3)+\text { Despesas Administrativas }(d 4)} \\
+ \text { Outras Despesas Operacionais }(d 8)]\end{array}}{\text { Ativo total }}$ \\
\hline $\begin{array}{l}w_{2 i t}: \text { Custo de } \\
\text { captação }\end{array}$ & $\begin{array}{l}\text { BCB }(2017) \\
\text { BCB }(2018) \\
\text { Ornelas et al. (2020) } \\
\text { Turk-Ariss (2010) }\end{array}$ & $w_{2}=\left[\frac{\text { Despesas de Captação }(b 1)}{\text { Depósito Total }(a)}\right]$ \\
\hline $\begin{array}{l}y_{1 i t}: \text { Produtos } \\
\text { financeiros de crédito }\end{array}$ & $\begin{array}{l}\text { BCB (2017) } \\
\text { BCB (2018) } \\
\text { Ornelas et al. (2020) }\end{array}$ & $y_{1 i t}=[$ Operações de Crédito Líquidas de Provisão $(d)+$ Arrendamento Mercantil Líquido de Provisões $(e)]$ \\
\hline $\begin{array}{l}y_{2 i t}: \text { Produtos financeiros } \\
\text { de ativos líquidos }\end{array}$ & $\begin{array}{l}\text { BCB (2018) } \\
\text { BCB (2017) } \\
\text { Ornelas et al. (2020) }\end{array}$ & $y_{2 i t}=$ Disponibilidades $(a)+$ Aplicações Interfinanceiras de Liquidez $(b)+$ Títulos,Valores Mobiliários e Instrumentos Derivativos $(c)$ \\
\hline$y_{3 i t}:$ Outros ativos & $\begin{array}{l}\text { BCB (2018) } \\
\text { BCB (2017) } \\
\text { Ornelas et al. (2020) }\end{array}$ & $y_{3 i t}=$ Outros Créditos Líquido de Provisão $(f)+$ Outros Ativos Realizáveis $(g)+$ Permanente Ajustado $(h)$ \\
\hline
\end{tabular}

Nota. Fonte: Elaborado pelos autores. 


\section{Técnicas de estimativa e de análise}

A partir da amostra contendo informações contábeis de 1.720 IF ao longo de 77 trimestres, formou-se um painel não balanceado com 80.849 dados considerados na estimativa da variável dependente custo total cuja expressão geral é representada pela Equação (6). Um painel é formado quando se combinam séries de tempo com dados transversais. O Statistical Analysis Software Studio OnDemand for Academics (SAS) foi utilizado para construir a base de dados e para obter os indicadores de concentração de competição.

$$
y_{i t}=\alpha_{i t}+\Sigma \beta X_{i t}+\varepsilon_{i t}
$$

Onde:

$y_{i t}$ : custo total da IF ${ }_{i}$ no período $t$;

$\mathrm{X}_{\mathrm{jit}}$ : vetor de produtos financeiros e preços dos insumos da $I F_{i}$ no período t;

$i$ : unidades cross-section; e

$t$ : unidades de série de tempo.

Na função translog do custo total, os fatores de produção são quantificados por meio do logaritmo natural dos valores medidos em termos relativos, pois representam preços dos insumos, conforme BACEN (2018), Ornelas et al. (2020), Maghyereh e Awartani (2014) e Turk-Ariss (2010). Aos valores absolutos dos produtos financeiros também são aplicados o logaritmo neperiano. As escalas logarítmicas permitem reduzir grandezas de elevada magnitude para uma escala menor.

Os parâmetros da função translog do custo total são estimados mediante regressão linear múltipla aplicada aos dados dispostos no painel não balanceado, formado via proxies das variáveis que integram o modelo representado pela Equação (4). Na sequência, esses parâmetros são utilizados na função do custo marginal do produto crédito para cada IF em cada período, de acordo com a Equação (5). Com os resultados do custo marginal e do preço das operações de empréstimo, cujo cálculo é indicado na Tabela 1, obtém-se o Indicador de Lerner.

Os índices de concentração, IHH e RC5, são apurados de acordo com as Equações (1) e (2) e proxies apresentadas na Tabela 1. De posse dos indicadores de concentração e de competitividade, mensurado pela média e seus quartis, é possível promover análises acerca do comportamento de cada um deles em separado e conjuntamente. Destaque foi dado ao período que sucede a última crise financeira mundial e a implantação da regulação prudencial de requerimento de capital. Ainda, em face da heterogeneidade da distribuição do Lerner, compara-se os níveis de concorrência observados em cada TCB.

\section{ANÁLISE EMPÍRICA, DESCRITIVA E RESULTADOS}

\section{Estimação do custo total}

Para identificar o nível de competição do sistema faz-se necessário, primeiramente, estimar o custo total (TC) via modelo econométrico de regressão múltipla onde: $T C=f$ (custo operacional, custo de captação, produtos financeiros).

Ao regredir uma variável de série temporal sobre outras variáveis que também seguem série de tempo, é necessário que as séries envolvidas sejam estacionárias, caso contrário, um alto coeficiente de determinação $\left(\mathrm{R}^{2}\right)$ pode refletir uma relação espúria. Um processo estocástico estacionário ocorre se a média e a variância forem constantes ao longo do tempo e o valor das covariâncias entre dois períodos depender apenas da defasagem ente eles.

Maddala e Wu (1999) e Choi (2001) propuseram o teste desenvolvido por Fisher (1932) o qual baseia-se na combinação dos valores do p-valor e do Augmented Dickey-Fuller (ADF) para cada unidade cross-section. Trata-se de teste não paramétrico cuja hipótese nula $\left(\mathrm{H}_{0}\right)$ é a de que todos os painéis contêm raiz unitária. Os resultados apresentados pelo SAS indicam rejeição de $\mathrm{H}_{0}$ ao nível de significância estatística de $1 \%$, o que era esperado para variáveis medidas em termos relativos.

Vale ressaltar que os quatro tipos de teste Fisher-Type rejeitaram a hipótese nula de que todos os painéis contêm raízes unitárias ao nível de significância de 1\%: Fisher Test Qui-quadrado, Asymptotic Fisher test, Inverse Normal Test e Logit Test. Choi (2001) recomenda o Inverse Normal Test, correspondente à estatística Z (distribuição normal), nas análises. Observa-se, ainda, que o Logit Test $L^{*}$ (distribuição $t$ ) corrobora o teste $Z$, o que geralmente ocorre. Por conseguinte, prevalece a hipótese alternativa da estacionariedade dos painéis.

Quanto ao método de estimação dos parâmetros, modelos construídos a partir de painel utilizam ferramentas específicas de acordo com a estrutura do termo de erro. O termo de erro $\left(\varepsilon_{\mathrm{it}}\right)$, que captura o que deixou de ser explicado sobre a variável dependente, decompõe-se no termo que varia no tempo das unidades de observação $\left(v_{\mathrm{it}}\right) \mathrm{e}$ no distúrbio das unidades específicas $\left(u_{\mathrm{i}}\right)$. $\mathrm{O}$ erro que 
reflete características individuais não observadas pode afetar a variável dependente.

O teste de especificação de Hausman (1978) foi utilizado para avaliar o ajuste de modelos de efeitos fixos e de efeitos aleatórios. A hipótese nula de ausência de correlação entre os efeitos (individuais ou temporais) e os regressores foi rejeitada ao nível de significância de $1 \%$, favorecendo a especificação de efeitos fixos. Sob $\mathrm{H}_{0}$, o estimador de efeitos fixos é consistente (convergente assintoticamente para os valores reais dos parâmetros da população), mas ineficiente (não possui variância mínima), enquanto o estimador de efeitos aleatórios é consistente e eficiente. Sob a hipótese alternativa apenas o estimador de efeitos fixos permanece consistente, pois há correlação entre os efeitos e as variáveis explicativas.

Verifica-se, ainda, que o teste $\mathrm{F}$ de efeitos individuais sugere heterocedasticidade nas observações, o que fortalece a escolha por um modelo em painel de efeitos fixos. Ao nível de $1 \%$ de significância, a hipótese nula de homocedasticidade foi rejeitada, concluindo-se, portanto, que os interceptos não são todos iguais, satisfazendo a suposição do modelo de $\mathrm{n}$ interceptos diferentes. Os estimadores de efeitos fixos consistem na opção mais adequada para modelar dados em painel quando o intercepto é correlacionado com as variáveis explicativas em qualquer período de tempo.

Uma vez atendidos os pressupostos econométricos, verifica-se a significância estatística dos coeficientes e as métricas de ajuste global do modelo de estimação do custo total (TC). Em seguida, o custo marginal ( $\mathrm{Cmag}$ ) é calculado mediante derivação da função custo total em relação às operações de crédito. O Índice de Lerner, portanto, pode ser calculado pela diferença entre o preço agregado e o custo marginal, em proporção do preço. Os resultados dos testes e os parâmetros da regressão linear normal múltipla da variável dependente custo total (TC), com intervalo de confiança de 95\%, considerando efeitos fixos, encontram-se na Tabela 3.

Tabela 3. Função translog do custo total: coeficientes e resultados dos testes da regressão.

\begin{tabular}{|c|c|c|c|c|c|c|}
\hline \multirow{2}{*}{$\begin{array}{l}\text { Variável } \\
\text { Intercept }\end{array}$} & \multirow{2}{*}{$\begin{array}{c}\text { Coeficiente } \\
-2,7708\end{array}$} & \multirow{2}{*}{$\begin{array}{c}\text { Erro Padrão } \\
0,0608\end{array}$} & \multicolumn{2}{|c|}{ Intervalo de Confiança (95\%) } & \multirow{2}{*}{$\begin{array}{r}\text { t-Valor } \\
-45,54\end{array}$} & \multirow{2}{*}{$\frac{p \text {-Valor }}{<0,0001}$} \\
\hline & & & $-2,8924$ & $-2,6492$ & & \\
\hline lnylit & 0,3531 & 0,0088 & 0,3355 & 0,3707 & 40,21 & $<0,0001$ \\
\hline $\ln y 2 i t$ & 0,3369 & 0,0050 & 0,3270 & 0,3469 & 67,99 & $<0,0001$ \\
\hline $\operatorname{lny} 3 i t$ & 0,3115 & 0,0064 & 0,2987 & 0,3244 & 48,59 & $<0,0001$ \\
\hline lny1itlny2it & $-0,0459$ & 0,0008 & $-0,0475$ & $-0,0442$ & $-55,52$ & $<0,0001$ \\
\hline lny1itlny3it & $-0,0670$ & 0,0012 & $-0,0693$ & $-0,0647$ & $-58,50$ & $<0,0001$ \\
\hline lny2itlny3it & $-0,0392$ & 0,0008 & $-0,0407$ & $-0,0376$ & $-50,69$ & $<0,0001$ \\
\hline lnylitlnylit & 0,0569 & 0,0007 & 0,0554 & 0,0583 & 79,62 & $<0,0001$ \\
\hline lny2itlny2it & 0,0406 & 0,0004 & 0,0398 & 0,0414 & 101,97 & $<0,0001$ \\
\hline lny3itlny3it & 0,0532 & 0,0007 & 0,0519 & 0,0545 & 81,41 & $<0,0001$ \\
\hline lnw1itw2it & 0,8505 & 0,0087 & 0,8332 & 0,8678 & 98,30 & $<0,0001$ \\
\hline lnw1itw2it2 & $-0,0136$ & 0,0006 & $-0,0147$ & $-0,0125$ & $-23,80$ & $<0,0001$ \\
\hline lny1itlnw1itw2it & $-0,0049$ & 0,0012 & $-0,0074$ & $-0,0025$ & $-4,07$ & $<0,0001$ \\
\hline lny2itlnw1itw2it & $-0,0187$ & 0,0008 & $-0,0203$ & $-0,0170$ & $-22,50$ & $<0,0001$ \\
\hline lny3itlnw1itw2it & 0,0071 & 0,0011 & 0,0048 & 0,0093 & 6,26 & $<0,0001$ \\
\hline $\mathrm{R} 2$ & \multicolumn{2}{|c|}{0,9709} & & & & \\
\hline Hausman & \multicolumn{2}{|c|}{$\begin{array}{c}\mathrm{m}=795,66 \\
\mathrm{p} \text {-valor }<0,0001\end{array}$} & & & & \\
\hline Teste - F & \multicolumn{2}{|c|}{$\begin{array}{c}F=22,06 \\
p \text {-valor }<0,0001\end{array}$} & & & & \\
\hline Teste de Fisher & \multicolumn{2}{|c|}{$\begin{array}{c}\chi 2=12384,0 \\
p \text {-valor }<0,0001\end{array}$} & & & & \\
\hline
\end{tabular}

Nota. Fonte: Elaborado pelos autores com base na análise estatística fornecida pelo SAS. 
No que tange ao ajuste global do modelo, o $\mathrm{R}^{2}$ ( $R$-Square), que representa o percentual da variável endógena explicado pelas exógenas, mostrou-se elevado. A Root Mean Square Error of Aproximation (RMSE) ou raiz do erro quadrático médio, que corresponde à quantidade de erro de aproximação populacional em uma matriz de covariância, foi calculado em 0,3982. Quanto mais baixo seu valor, maior a acurácia do modelo.

Localmente, o modelo se mostrou bem ajustado pois o teste 't de student' apontou para a significância estatística dos coeficientes das variáveis exógenas, indicando, portanto, que os parâmetros são estatisticamente diferentes de zero ao nível de significância de $1 \%$. Em outras palavras, a probabilidade de cometer o erro tipo I, ou seja, de rejeitar a hipótese nula, $\mathrm{H}_{0}: \lambda=0$, sendo esta verdadeira, encontra-se em nível aceitável ( $\mathrm{p}$-valor < 1\%). Além disso, os parâmetros das variáveis independentes estão associados a um baixo erro padrão.

Vale registrar que ao atender aos pressupostos econométricos, é possível interpretar os sinais e a magnitudes dos coeficientes da função translog do custo (Albuquerque, 1987). Taxas médias de crescimento dos preços dos fatores de produção, elasticidades-preço e elasticidades de substituição são conceitos relevantes que podem ser analisados via parâmetros da regressão do custo total. Tais interpretações microeconômicas têm o potencial de constituir tema de estudo específico que vise aprofundar a avaliação da eficiência bancária no mercado de crédito.

\section{Análise descritiva}

Para melhor compreensão dos resultados e das análises dos indicadores de competição, que serão analisados na seção seguinte, é importante apresentar as estatísticas descritivas referentes a cada TCB considerados neste artigo. A Tabela 4 apresenta a análise descritiva do Indicador de Lerner cujos resultados sugerem a existência de uma distribuição assimétrica negativa (ou à esquerda), ou seja, há maior concentração de valores superiores à média. Vale acrescentar, ainda, que as cooperativas de crédito singular (b3S) apresentaram o menor mark-up médio e mediano entre os TCB considerados. Enquanto as instituições não-bancárias de crédito (n1) registraram o maior mark-up médio e mediano no período.

Tabela 4. Estatística descritiva do Indicador de Lerner por TCB.

\begin{tabular}{lcccc}
\hline & b1 & b2 & b3S & n1 \\
\hline Mínimo & $-0,99$ & $-0,92$ & $-0,99$ & $-0,93$ \\
$1^{\circ}$ Quartil & 0,74 & 0,75 & 0,65 & 0,81 \\
\hline Média & 0,77 & 0,77 & 0,72 & 0,85 \\
\hline Mediana (2` Quartil) & 0,85 & 0,84 & 0,76 & 0,88 \\
\hline $3^{\circ}$ Quartil & 0,90 & 0,90 & 0,85 & 0,95 \\
\hline Máximo & 1,00 & 0,99 & 0,99 & 0,99 \\
Desvio-Padrão & 0,25 & 0,24 & 0,21 & 0,17 \\
Coeficiente de Variação & 33,83 & 31,22 & 29,82 & 20,70 \\
Assimetria & $-3,12$ & $-3,52$ & $-2,77$ & $-4,19$ \\
Curtose & 12,27 & 15,77 & 12,19 & 27,50 \\
\hline
\end{tabular}

Nota. Fonte: Elaborado pelos autores com base na análise estatística fornecida pelo SAS.

Resultados do IHH, do RC5 e do Indicador de Lerner

\section{Índices de concentração versus de competição}

A literatura científica não apresenta consenso sobre o nexo entre competição e concentração no âmbito da indústria financeira. Os resultados do IHH sugerem que a concentração do sistema bancário e não bancário atuante no crédito $(\mathrm{b} 1+\mathrm{b} 2+\mathrm{b} 3 \mathrm{~S}+\mathrm{n} 1)$ se elevou de baixa $(0,07)$ para moderada $(0,13)$ ao longo do período amostral considerado. No que se refere à RC5, Caixa, BB, Itaú-Unibanco, Bradesco e Santander controlavam $72,2 \%$ dos créditos no I tri 2019 , ante $45,4 \%$ de participação no I tri 2000.
A despeito do aumento da concentração, a média do Indicador de Lerner do sistema, ponderada pelo volume de crédito ofertado por cada IF em relação ao TCB que pertence, encerrou o I tri 2019 em patamar semelhante ao do I tri 2000 , de 0,8 . Portanto, a concorrência não se deteriorou no período. Ao analisar a competitividade pela mediana do Lerner, que descarta os maiores e menores Índices, há uma melhora da competição. A correlação entre a mediana do Índice de Lerner e o IHH foi igual a $4,8 \%$ e entre o Lerner e a RC5, a -0,72\%. As Figuras 1 e 2 permitem visualizar o comportamento dos indicadores de concentração comparativamente ao de competição. 


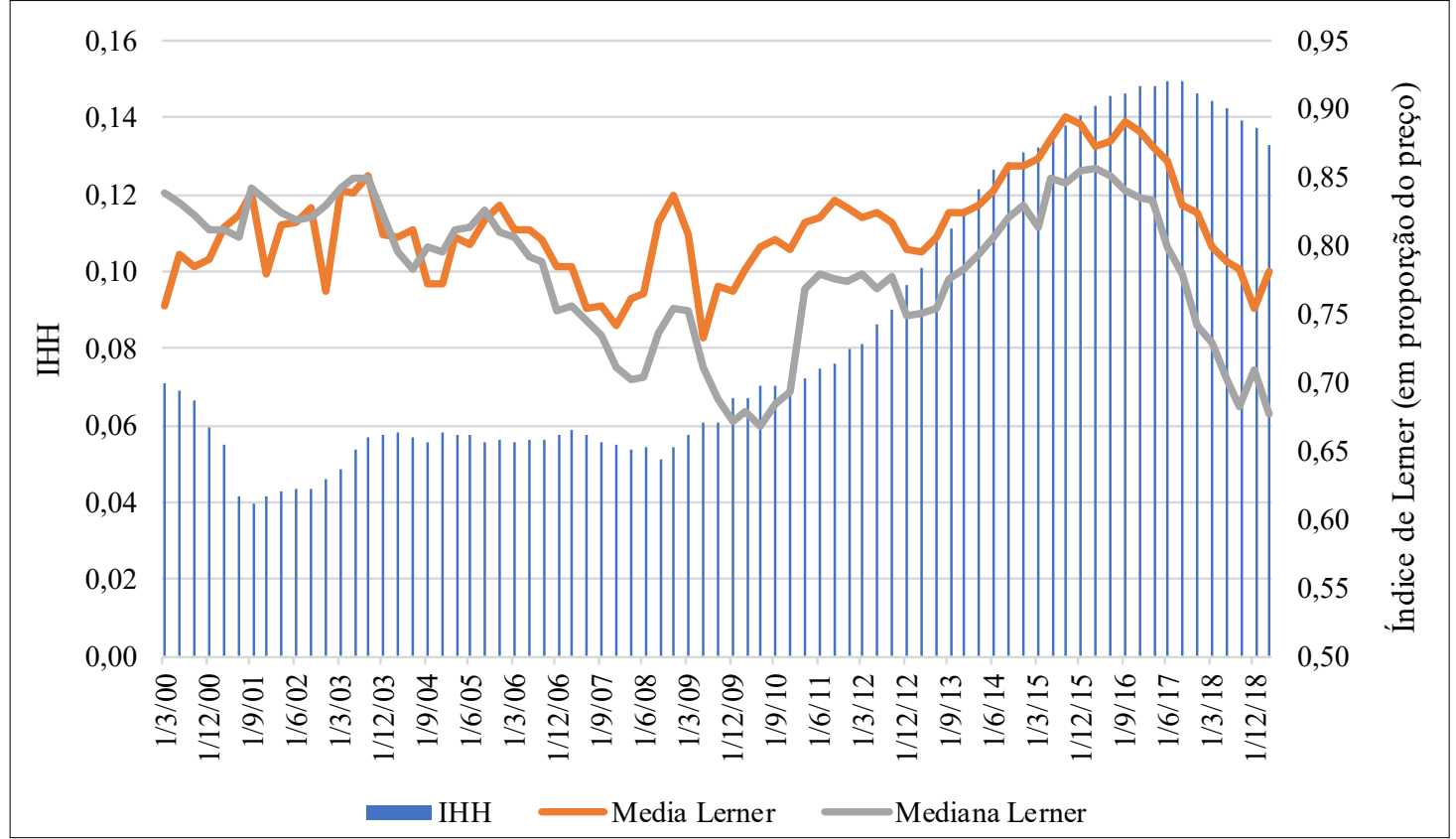

Figura 1. IHH versus Índice de Lerner.

Fonte: Elaborado pelos autores.

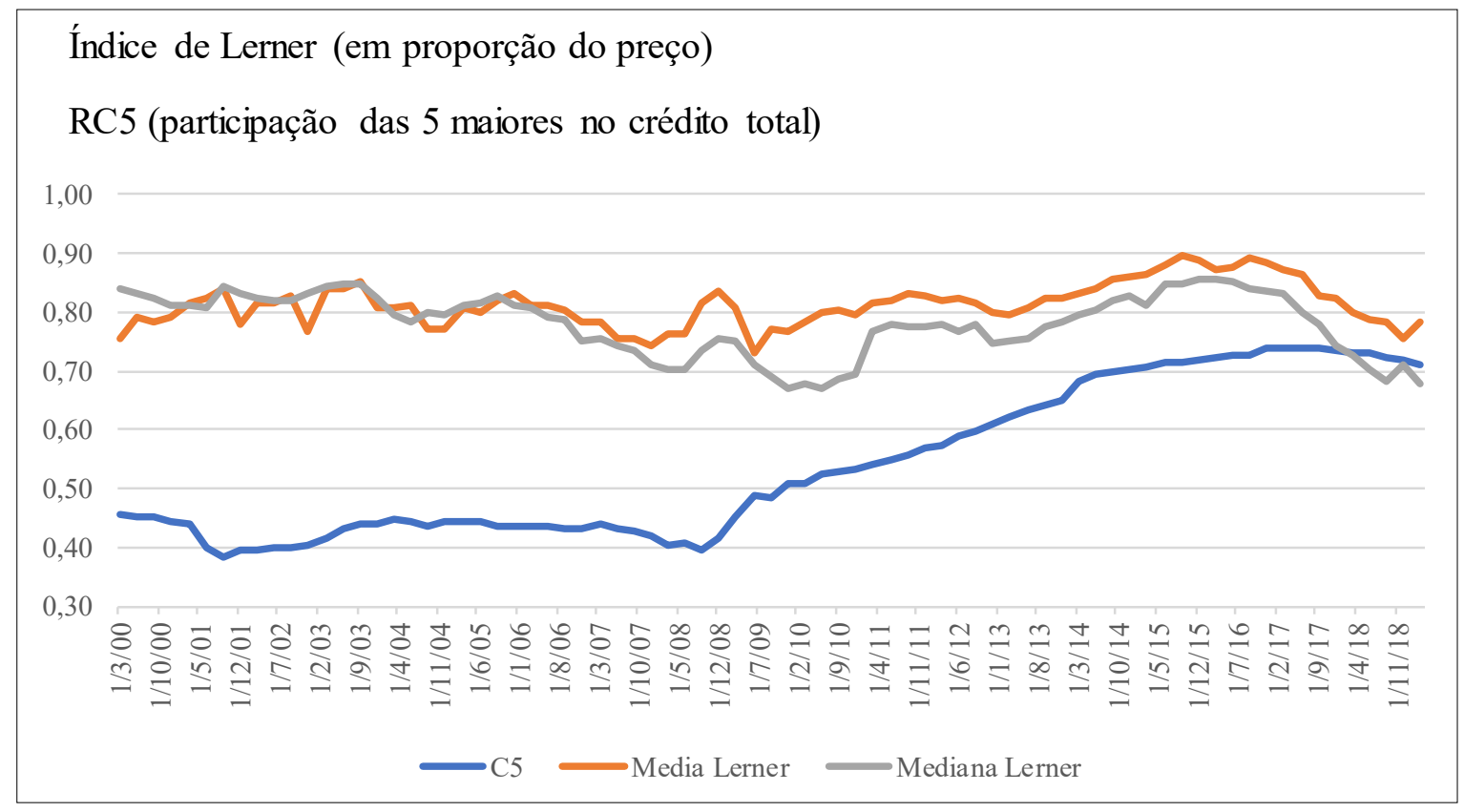

Figura 2. RC5 versus Índice de Lerner.

Fonte: Elaborado pelos autores.

A concentração explica-se, em parte, pela necessidade de ganhos de escala, de altos investimentos e da complexa gestão de riscos do setor. Além disso, com a crise de 2008 o mercado tornou-se mais concentrado, com eventos de fusões e de aquisições relevantes. O aumento também foi percebido na maior parte dos países com a eclosão da instabilidade financeira internacional, segundo estudo do Bank for International Settlements (BIS) (2018).

Após a turbulência financeira internacional, mais especificamente a partir do III tri 2009, os mark-ups de crédito subiram, ou seja, a 
competição deteriorou-se até 2016, mesmo com a queda da taxa Selic em meados de 2009. Contudo, o aperto monetário iniciado em meados de 2013, com a Selic à $7,5 \%$ ao ano, até o final de 2016, com a Selic à $14,5 \%$ ao ano pode ter contribuído para a elevação das margens dos empréstimos concedidos pelo setor. Além do aumento do custo de oportunidade, vale lembrar que as IF enfrentaram elevação da inadimplência em razão da crise econômica doméstica nesse período.

Os indicadores de concentração, porém, mostraram ser relativamente mais persistentes que o de concorrência, que já voltou ao nível anterior à crise (III tri 2008). A queda dos juros desde o final de 2016 até o início 2019, em mais de 8 pontos percentuais, pode ter influenciado na redução dos mark-ups de crédito a partir de 2017. Além disso, a competição pode ter aumentando devido a aspectos regulatórios, como a proporcionalidade da regulação prudencial de requerimento de capital, como sugere a literatura mais recente (Claessens \& Laeven, 2004).

A Resolução $n^{\circ}$ 4.553/2017 (Conselho Monetário Nacional [CMN], 2017), publicada em 30 de janeiro de 2017, separou as IF em cinco segmentações. Na segmentação S1, encontramse os bancos cujo porte, medido pela exposição total, é igual ou superior a $10 \%$ do PIB ou que sejam internacionalmente ativos. O S2 agrupa bancos de tamanho inferior à $10 \%$ do PIB e demais IF com tamanho superior à $1 \%$ do PIB. O S3 contém bancos e instituições não bancárias de porte entre
0,1\% e 1\% do PIB. Os bancos e as IF não bancárias de tamanho inferior a $0,1 \%$ do PIB se enquadram em S4. Desse último, as cooperativas de crédito e as instituições não bancárias que tenham perfil de risco simplificado se enquadrarão no S5.

Assim, os requisitos exigidos nos Acordos de Basileia tornaram-se válidos para os bancos com atividade internacional relevante, reunidos no segmento S1. Para as instituições classificadas nas outras segmentações, as normas passaram a serem aplicadas proporcionalmente, contribuindo para aumentar a competição no mercado brasileiro. Ao seguir uma regra prudencial de complexidade adequada às suas atividades, a IF pode competir de maneira mais igualitária com as demais.

A análise da Figura 3 apoia a perspectiva de que as margens do crédito se reduziram a partir a Regulação sobretudo nos segmentos cujos requerimentos foram flexibilizados. As cooperativas de crédito e as instituições não bancárias cujo perfil de risco simplificado se enquadraram no $\mathrm{S} 5$ registram as maiores quedas do Índice de Lerner.

A heterogeneidade na distribuição do Índice de Lerner revela a importância de apresentar o Indicador de competitividade em termos de quartis, ainda, incita uma avaliação de cada ТСB separadamente, conforme mostram as próximas seções.

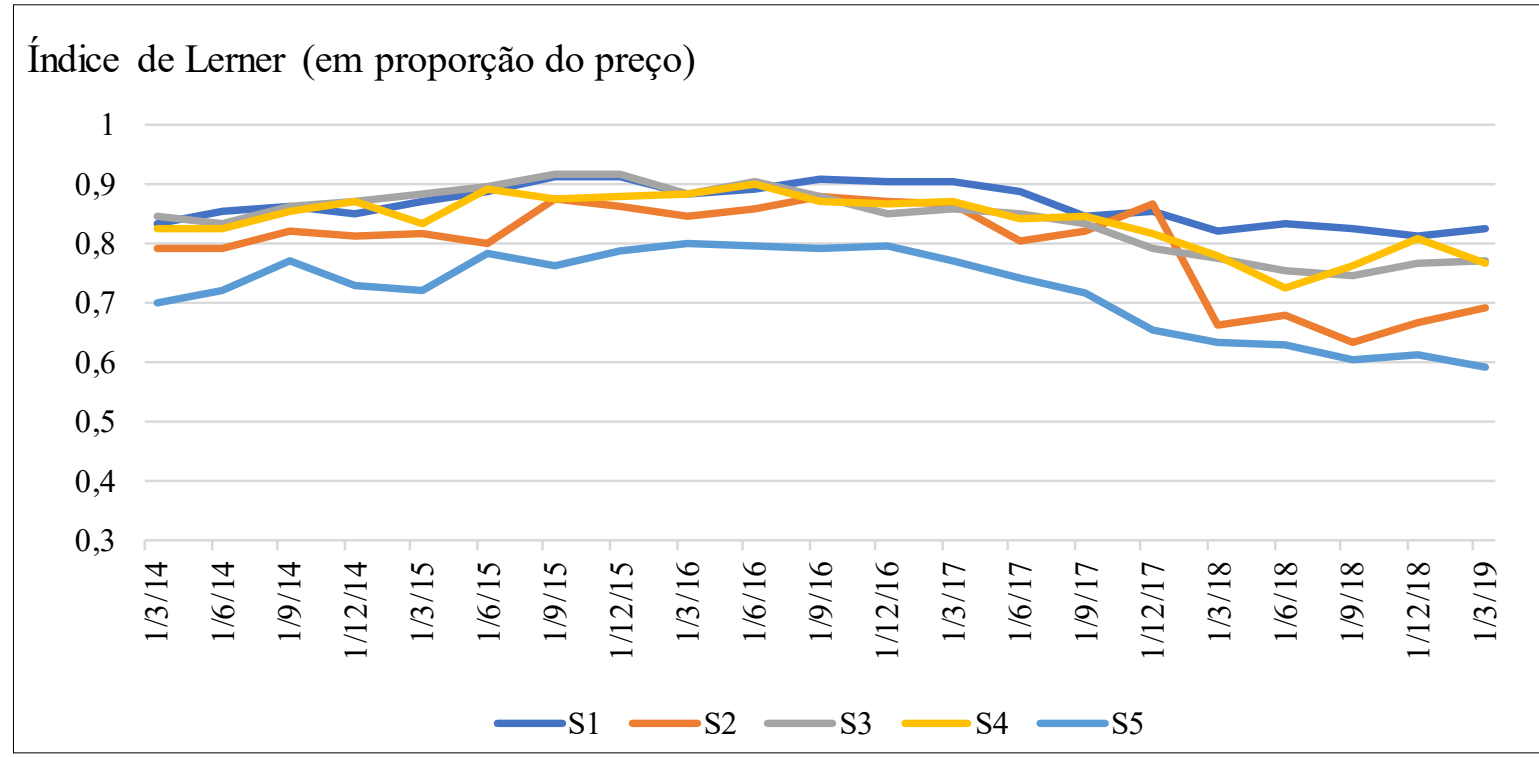

Figura 3. Mediana dos Índices de Lerner por segmentação.

Fonte: Elaborado pelos autores. 


\section{Índice de competição}

As instituições maximizadoras de lucros com relativo poder de mercado buscam aplicar um markup sobre seus custos marginais em ofertar crédito. Em ambientes competitivos a maior elasticidade da demanda por crédito em relação aos juros tende a limitar o valor das taxas doa empréstimos. Portanto, quanto maior o mark-up, menor o grau de concorrência no mercado. O Indicador de Lerner dos segmentos bancário b1 e b2 e do segmento não bancário b3S e $\mathrm{n} 1$, apresentou trajetória representada na Figura 4. A média foi ponderada pelo volume de crédito ofertado por cada IF em relação ao TCB que pertence. A mediana ou $2^{\circ}$ quartil, que consiste no valor até o qual se encontra $50 \%$ da amostra ordenada, é representada pela legenda p_50. O $1^{\circ}$ quartil, designado por p_25, é o valor que detém $25 \%$ das observações da amostra abaixo e $75 \%$ acima, enquanto o $3^{\circ}$ quartil (p_75) deixa $75 \%$ das observações abaixo e $25 \%$ acima.

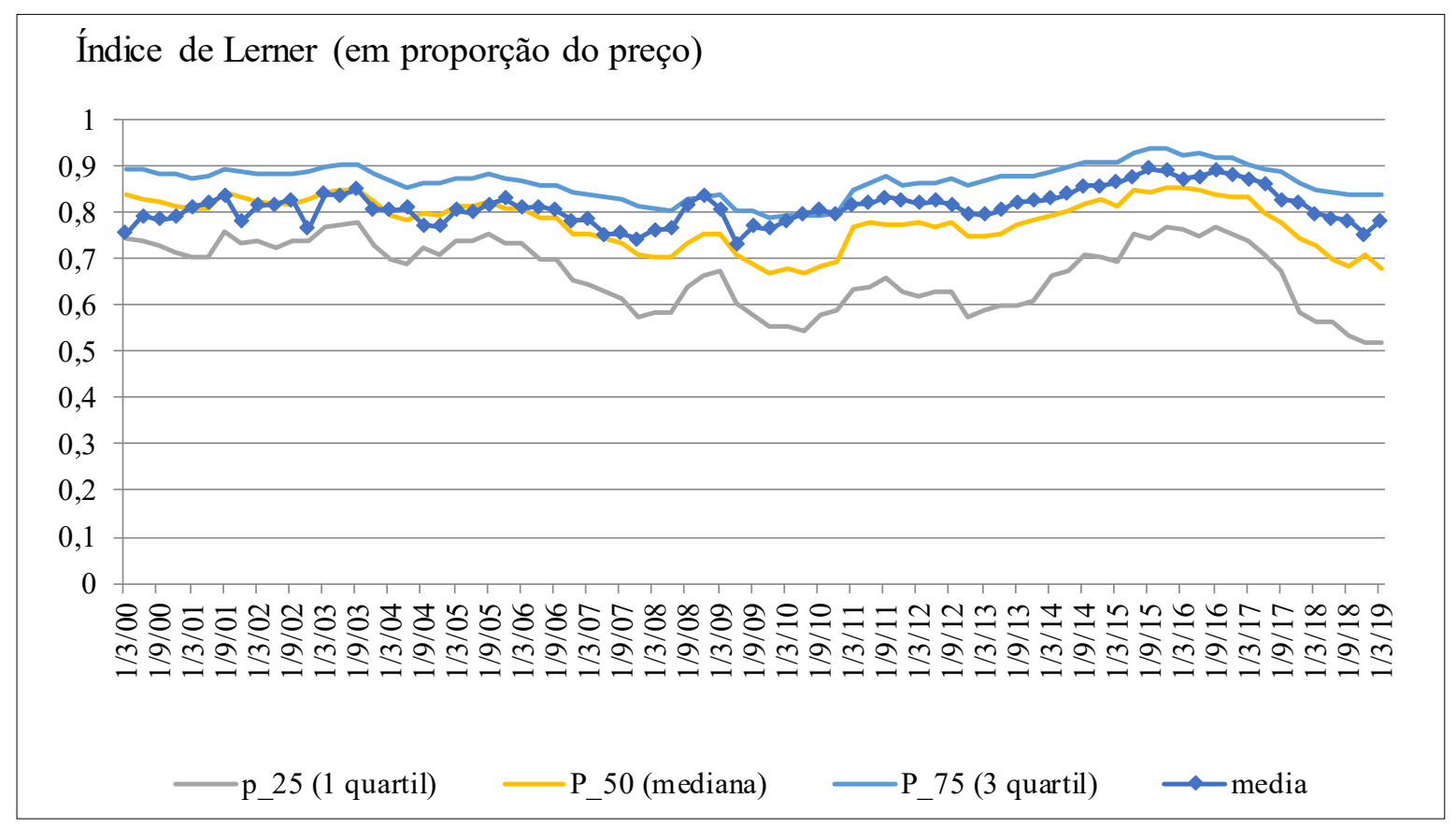

Figura 4. Índices de Lerner e seus quartis.

Fonte: Elaborado pelos autores.

A média ponderada do Indicador de Lerner segue dinâmica semelhante à apresentada pela mediana, todavia, o nível do indicador médio mostra-se superior na maior parte do período. Tal resultado indica que que IF de grande porte, como os bancos tipo b1, possuem Lerner na cauda superior da distribuição.

\section{Índice de competição das instituições bancárias}

Dada a relevância das instituições bancárias tipo b1 na concessão do empréstimo total, seus Índices de Lerner médios acompanham a trajetória e o nível da média do sistema, conforme mostra a Figura 5. A média do mark-up tanto para b1 quanto para b2, embora tenha variado ao longo da série, encerrou o I tri 2019 praticamente nos mesmos patamares registrados no início do período amostral, como pode ser visualizado na Figura 5 e 6.

A partir do III tri 2009, ou seja, 1 ano após a eclosão da crise financeira mundial, os Índices sobem, contribuindo para a piora da competição do sistema identificada na seção 5.3.1. Vale notar, ainda, o aumento da dispersão do Indicador de competição para b1 e para b2.

Desde o IV tri de 2016, no entanto, os bancos apresentaram queda dos seus mark-ups. Vale ressaltar que o indicador já reflete as operações de crédito realizadas pelos bancos digitais, a saber: ING Bank, Banco Original, Banco BS2, Banco Inter, Banco Modal e Banco Neon. Juntos, os bancos digitais representavam $0,8 \%$ do total dos empréstimos líquidos de provisão concedidos pelo sistema. 


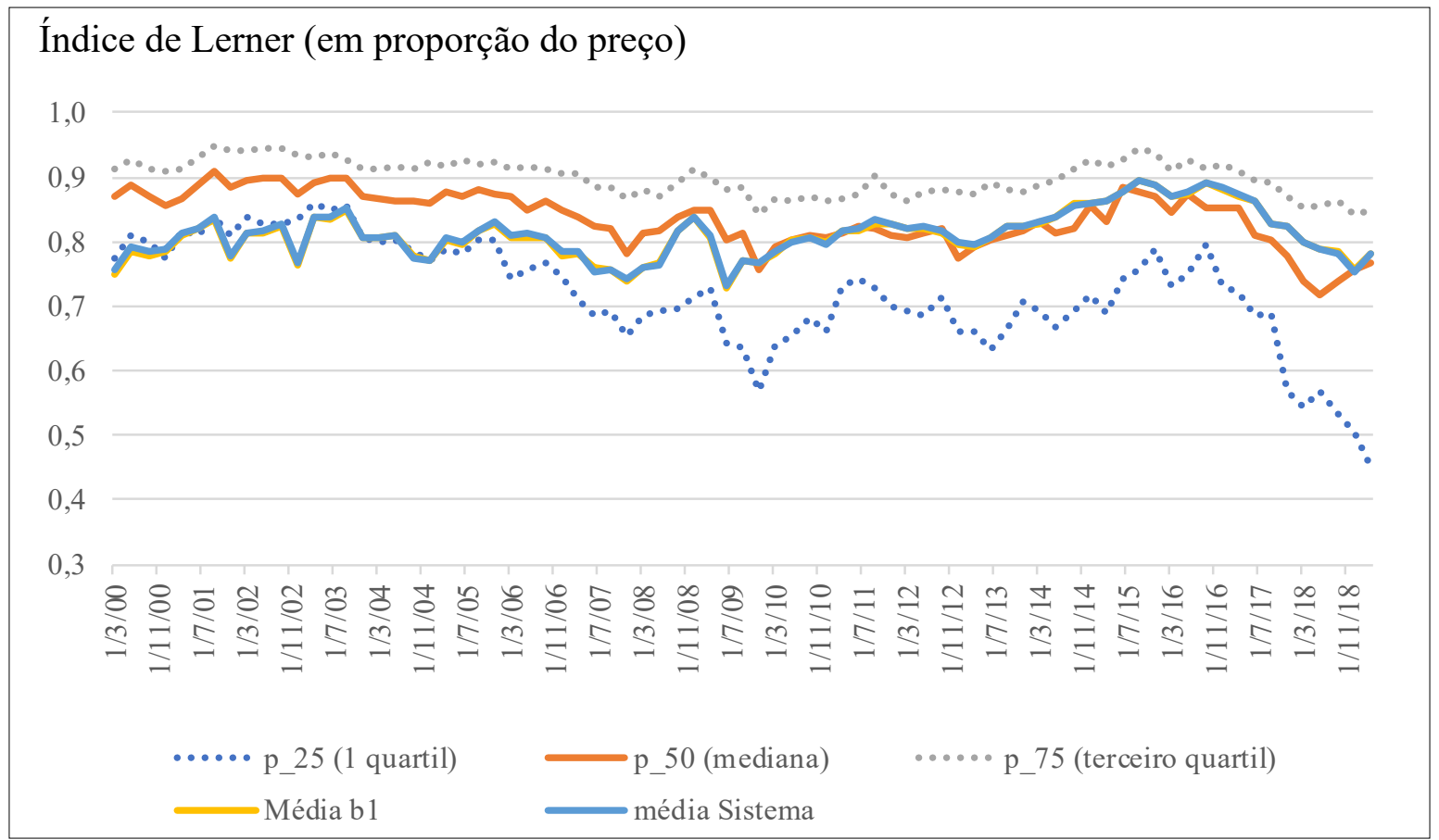

Figura 5. Índices de Lerner das instituições bancárias tipo b1.

Fonte: Elaborado pelos autores.

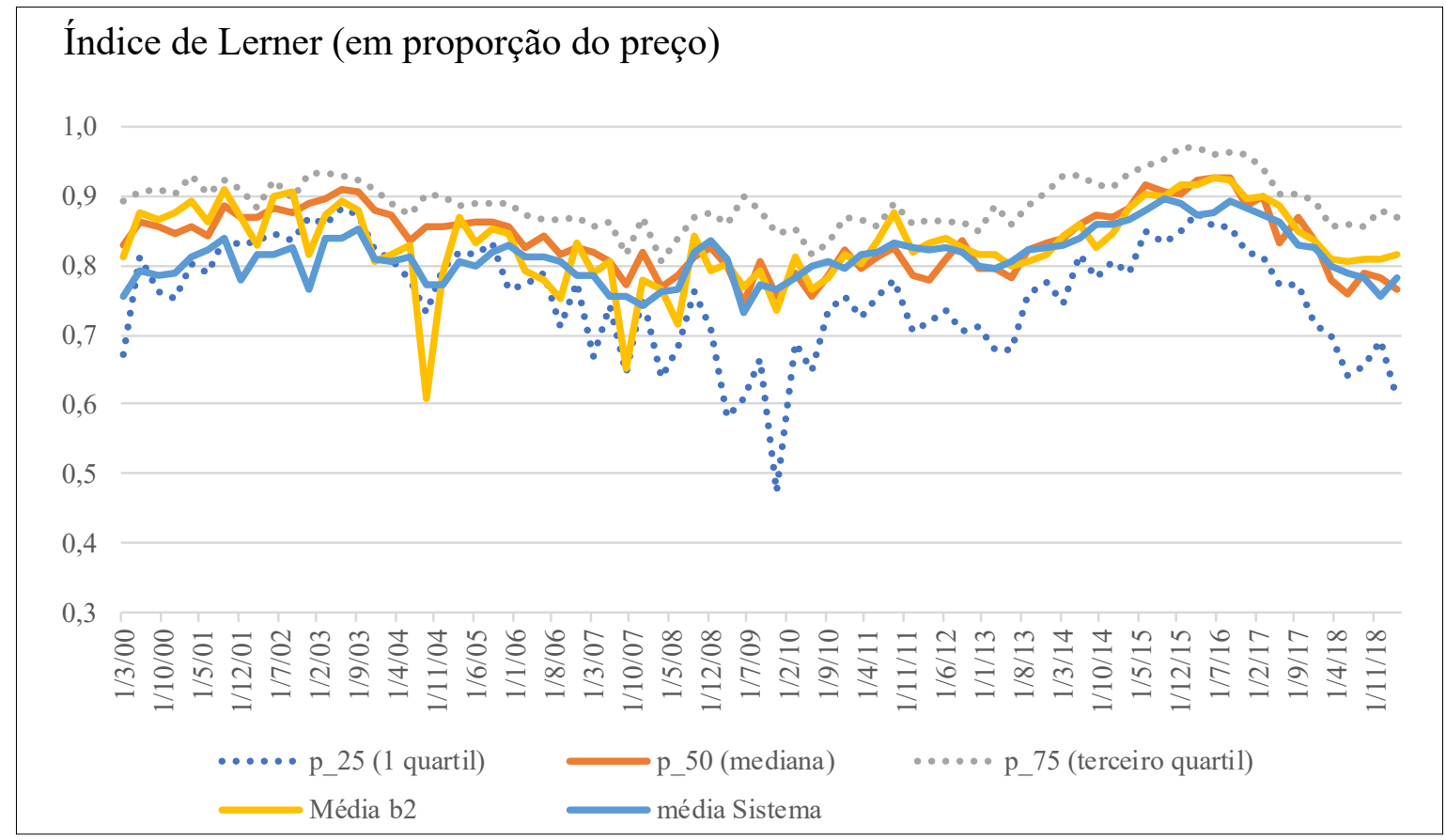

Figura 6. Índices de Lerner das instituições bancárias tipo b2.

Fonte: Elaborado pelos autores.

Índice de competição das instituições não bancárias

No tocante ao segmento não bancário, a média do mark-up das cooperativas de crédito singular
(b3S) apresentou queda no período analisado pela presente pesquisa, de 0,80 para 0,67 , como mostra a Figura 7. Após 2 anos do início da crise financeira mundial essas instituições elevaram suas margens de taxas sobre o crédito ofertado, mas por um curto 
período de tempo. A partir de 2017, assim como ocorreu no segmento bancário, registraram aumento da competitividade. A queda recente do Indicador de Lerner das IF não bancárias pode ter sido influenciada pela flexibilização da política monetária e pela entrada em vigor da regulação prudencial de requerimento de capital proporcional Embora as cooperativas não visem lucro, buscam maximizar o benefício usufruído por seus cooperados e manter seus projetos sustentáveis, o que permite avaliar sua competitividade por meio do Indicador de Lerner. Interessante notar que, desde o começo do recorte temporal considerado, as cooperativas se destacaram por apresentar níveis médios de competitividade superiores que b1, b2 e n1, como mostra a Figura 8.

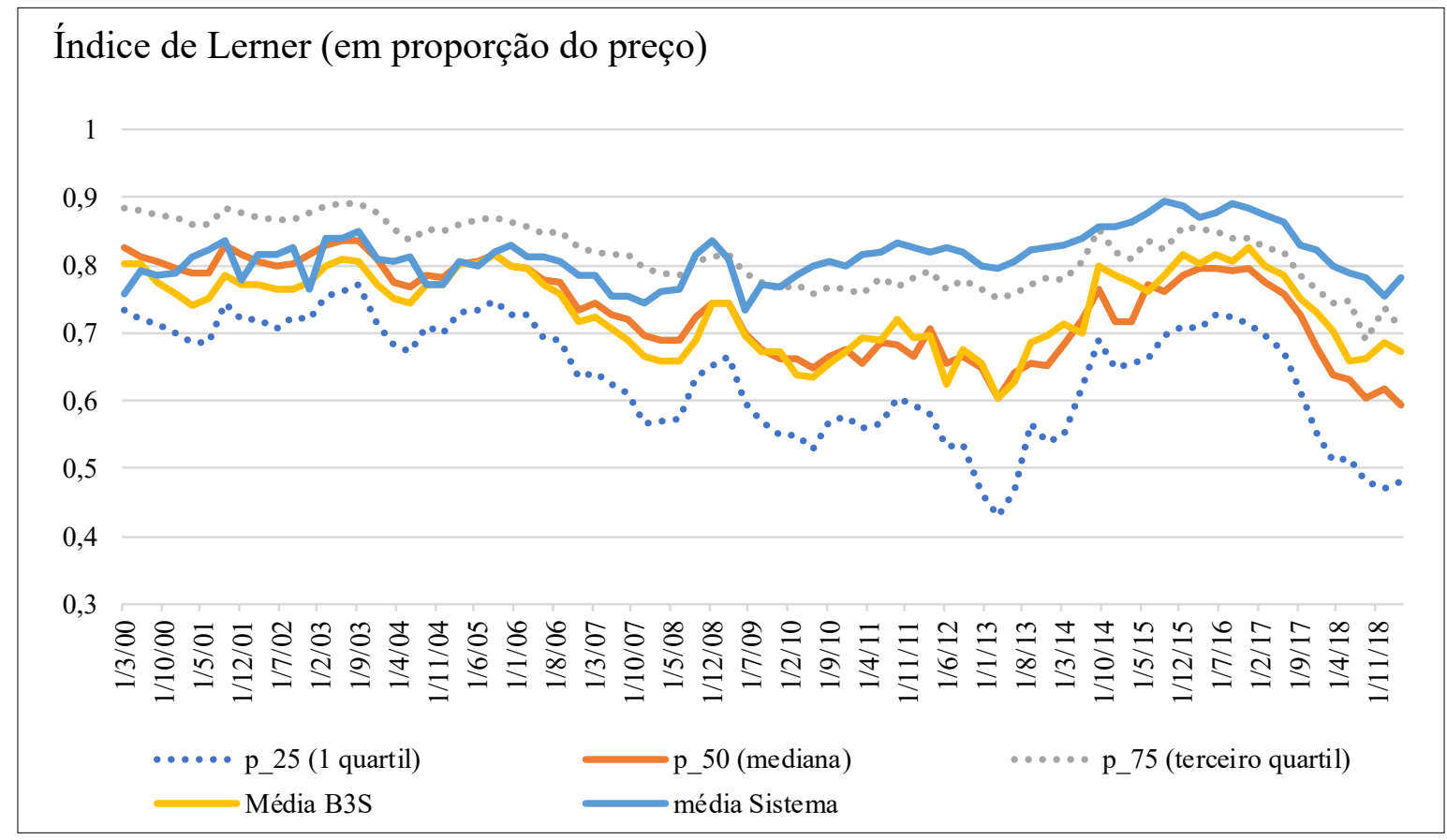

Figura 7. Índices de Lerner das Cooperativas de Crédito Singular (b3s).

Fonte: Elaborado pelos autores.

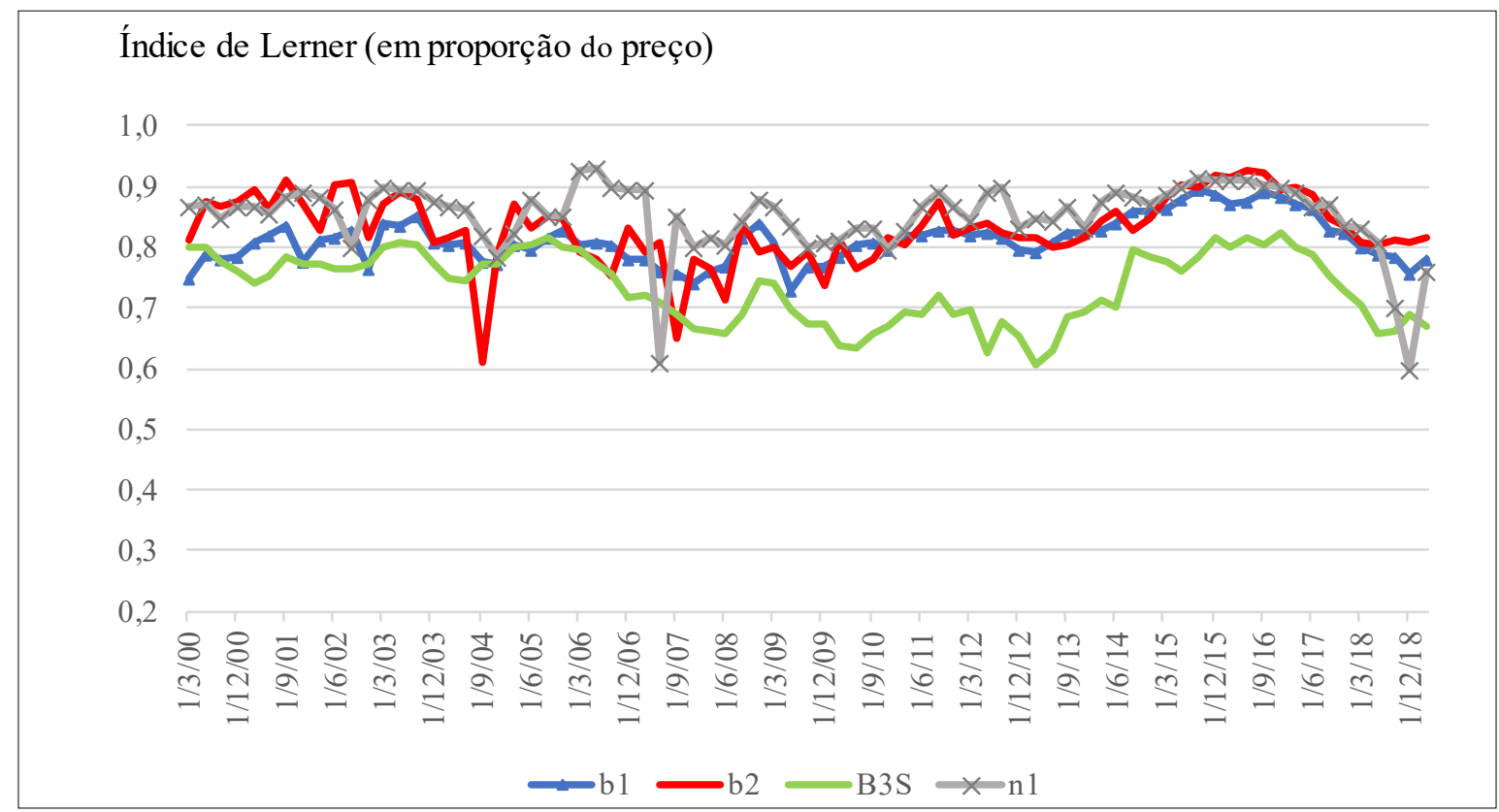

Figura 8. Índices de Lerner de b1, b2, b3S e n1.

Fonte: Elaborado pelos autores. 
As cooperativas, embora representem apenas 3,0\% dos empréstimos concedidos pelo sistema (III tri 2018), têm crescido em participação (BACEN, 2017), aumentando o potencial de acirrar a concorrência no mercado de crédito. A autoridade monetária destaca, ainda, que os juros praticados por essas instituições são inferiores àqueles praticadas pelo segmento bancário tipo b1. Uma possível explicação está no aumento da profissionalização e no consequente ganho de escala, bem como na desobrigação da busca de lucro, nos benefícios fiscais e na retroalimentação positiva entre cooperados e cooperativa.

As instituições não bancárias de crédito (n1) mantiveram a média ponderada de seus mark-ups em níveis elevados ao longo de toda a série. Além disso, seus Índices de Lerner foram superiores aos apresentados pelos demais TCB, sugerindo a menor competição desse grupo, como mostra a Figura 8. Essas instituições são responsáveis por 3,9\% das operações de crédito (III tri 2018).

\section{CONCLUSÃO}

Os indicadores de concentração relativos à indústria financeira doméstica atuante no crédito apresentaram aumento consistente entre o I tri 2000 e o I tri 2019, especialmente a partir de 2008. O IHH passou de baixo grau de concentração no início do período para moderado. As cinco maiores instituições, que controlavam $45,4 \%$ do mercado de crédito, passaram a controlar $72,2 \%$ ao final da série. $\mathrm{O}$ aumento da concentração do sistema pode ser explicado por questões estratégicas, como a busca por ganhos de escala e de escopo, bem como pela necessidade de altos investimentos e da complexa gestão de riscos do setor. Após a crise de 2008, fusões e aquisições relevantes contribuíram para a concentração, movimento observado e grande parte dos países (Bank for International Settlements, 2018).

A despeito do aumento da concentração, a mediana do Indicador de Lerner reduziu-se de 0,83 no I tri 2000 para 0,68 no I tri 2019 , ou seja, a concorrência aumentou. A média do Indicador, ponderada pelos empréstimos concedidos de cada IF no respectivo TCB, encerrou a série praticamente no mesmo patamar, sugerindo que instituições de grande porte não apresentaram redução nos seus mark-ups de crédito.

A comparação entre os indicadores de concentração e de competividade apoia a primeira hipótese de pesquisa, reforçando, ainda, a teoria Estrutura-Lucratividade, que argumenta não haver, necessariamente, um trade-off entre concentração e competição (VanHoose, 2010). Nessa perspectiva, ganhos de eficiências proporcionados por fusões e aquisições permitem que as IF reduzam juros sem perda de lucratividade. A existência de uma relação inversa entre concentração e juros do crédito tem prevalecido na literatura atual, de acordo com Fungácová, Shamshur e Weill (2017). Claessens e Laeven (2004) mostraram que mercados financeiros com menor barreira a entrada a novas organizações e a inovações financeiras podem ser competitivos e concentrados.

Vale ressaltar que a competição da indústria financeira atuante no crédito deteriorou-se após a eclosão da turbulência financeira internacional de 2008. Além do aumento do custo de oportunidade, com o aperto monetário iniciado em meados de 2013, vale lembrar que as IF enfrentaram elevação da inadimplência em razão da crise econômica doméstica nesse período. Contudo, os indicadores de concentração mostraram ser relativamente mais persistentes que os de concorrência, que já voltaram aos patamares pré-crise.

A média e a mediana do Lerner registraram redução expressiva a partir de 2017. Os resultados sugerem que a concorrência pode ter aumentado devido a questões regulatórias, principalmente a proporcionalidade da regulação prudencial de requerimento de capital, como aponta a literatura mais recente (Claessens \& Laeven, 2004) e a segunda hipótese de pesquisa. Com a implementação da Resolução $\mathrm{n}^{\circ}$ 4.553/2017 (Conselho Monetário Nacional [CMN], 2017), IF menores passaram a seguir regras mais simples que às aplicadas aos bancos de grande porte, contribuindo para aumentar a competição no mercado brasileiro.

Ademais, vale destacar a relevância das cooperativas de crédito, ampliando a oferta de crédito suplementar, assim como das inovações tecnológicas, que também impactam o funcionamento do sistema. Os grupos de IF que compõem o mercado de crédito nacional apresentam níveis de competição heterogêneos, nesse contexto, este artigo encontrou evidências de que a concorrência no segmento não bancário tipo b3S é maior que a observada no bancário tipo b1 e b2, conforme estabelece a terceira hipótese.

As empresas financeiras intensivas no uso de tecnologia, que inclui bancos digitais, fintechs e grandes companhias, evoluíram nos últimos anos, aumentando o potencial de estimular a concorrência no mercado de crédito. Urge lembrar que os indicadores de concentração e de competição estimados neste artigo levam em conta a entrada recente dos bancos digitais cujas informações contábeis encontram-se registradas no IF.data. Contudo, não há dados públicos disponíveis para cálculo dos índices referentes às fintechs, constituindo-se, portanto, uma limitação da pesquisa. 
Ao comparar o desempenho concorrencial por TCB, nota-se que o Índice de Lerner das instituições bancárias tipo b1 acompanha a trajetória e o nível da média do sistema. O mark-up médio tanto para b1 quanto para b2 fechou o I tri 2019 nos mesmos patamares registrados no início da série. A partir do III tri 2009, ou seja, 1 ano após o início da turbulência econômica mundial, os Îndices subiram, corroborando a perspectiva de que as grandes instituições, como os bancos, contribuíram para a piora da competitividade do sistema. Desde o IV tri de 2016, o segmento bancário apresentou melhora no nível de competição.

No tocante ao segmento não bancário, a média ponderada do mark-up das cooperativas de crédito singular (tipo b3S) foi a única que apresentou queda significativa no período analisado comparativamente aos demais TCB (b1, b2 e n1). Desde o começo do recorte temporal, as cooperativas se destacaram por apresentar níveis de competitividade superiores à b1, b2 e n1. As instituições não bancárias de crédito (n1) mantiveram seus mark-ups em níveis elevados ao longo da série e superiores aos apresentados pelos demais TCB, sugerindo a menor competição nesse tipo de consolidado bancário

Conclui-se, com fulcro no artigo conduzido e a despeito das limitações apontadas, que as estimativas e as análises da concorrência no âmbito do mercado de crédito brasileiro por si já preenchem uma lacuna de pesquisa. Diante da ausência de consenso acadêmico, este trabalho elucida, ainda, a relação entre concentração e competitividade, bem como traz à tona a relevância da regulação e das cooperativas de crédito sobre as margens praticadas nas operações de crédito.

A literatura teórico-empírica sobre a concorrência na indústria financeira é rara, especialmente em relação às nações em desenvolvimento (Bikker \& Haff, 2002; Turk-Ariss, 2010). Assim, o presente trabalho contribui para a epistemologia acadêmica e prática, ao se tornar útil para apoiar políticas de ordem microeconômica capazes de promover a contestabilidade. Iniciativas que flexibilizem restrições à entrada de instituições não bancárias e de empresas que operam com tecnologia podem contribuir para a queda das margens cobradas nas operações de crédito. Nesse contexto, espera-se que a Resolução n4.656/2018 (Conselho Monetário Nacional [CMN], 2018), que regulamentou a atuação das fintechs de crédito, estimule a competição no setor.

As estimativas de concentração e de competição devem avançar no sentido de incorporar outros países e demais produtos e serviços financeiros. As publicações dos estudos empíricos no âmbito internacional, em geral, se atêm à atividade bancária de forma agregada, e não às operações de crédito de forma apartada (Turk-Ariss, 2010). Assim, estudos futuros que estimem a competitividade no mercado de empréstimos global tendem a ganhar relevância. Nessa perspectiva, torna-se viável comparar, inclusive, o nível da concorrência nacional com o apresentado pela América Latina e Caribe, e por países competidores.

Pesquisas também merecem abranger outros produtos e serviços, como meios de pagamentos (cartões), transferências e depósitos e, dessa maneira, obter uma avaliação completa da competitividade. A ampliação de escopo se justifica pelo crescimento do mercado de pagamentos e pelo impacto recente da concorrência, em especial, no setor de adquirência. O desenvolvimento e a relevância da indústria de pagamentos não vêm acompanhados de trabalhos científicos. Não foram identificados, ainda, estudos específicos sobre a atividade de credenciamento. Akin, Aysan, Borici e Yildiran (2013) e Shaffer e Thomas (2007) avaliam o setor sob a ótica dos bancos emissores e concluíram que a regulação aumentou a competição no setor.

Identificar o impacto da concorrência sobre o risco sistêmico também constitui uma fecunda linha de pesquisa. Em virtude dos efeitos sistêmicos adversos, o regulador do sistema financeiro se pergunta quais fatores levam à iminência da quebra de um banco. No que concerne à relação entre competição e estabilidade, não há convergência. A vertente tradicional argumenta que sistemas bancários mais competitivos geram instabilidade, pois o poder de mercado reduziria a assimetria informacional e a exposição ao risco dos bancos. Evidências teórico-empíricas também indicam que a competição eleva a robustez dos bancos, pois a eficiência cria incentivos para selecionar e monitorar credores, reduzindo a inadimplência nos empréstimos concedidos. 


\section{REFERENCIAS}

Allen, F., \& Gale, D. (2004). Competition and financial stability. Journal of Money, Credit, and Banking, 36(3), 453-480. Retrieved from https:// econpapers.repec.org/article/mcbjmoncb/ v_3a36_3ay_3a2004_3ai_3a3_3ap_3a453-80.htm

Akin, G. G., Aysan, A. F., Borici, D., \& Yildiran, L. (2013). Regulate one service, tame the entire market: Credit cards in Turkey. Journal of Banking and Finance, 37(4), 11951204. https://doi.org/10.1016/j.jbankfin.2012.11.016

Albuquerque, M. C. C. (1987).Uma análise translog sobre mudança tecnológica e efeitos de escala: Um caso de modernização ineficiente. Pesquisa e Planejamento Econômico, 7(1), 191-220. Retrieved from http:// repositorio.ipea.gov.br/handle/11058/6027

Angelini, P., \& Ceterolli, N. (2003) The effects of regulatory reform on competition in the banking industry. Journal of Money, Credit, and Banking, 35(5), 663-684. https://doi.org/10.1353/mcb.2003.0033

Bank for International Settlements. (2018). Structural changes in banking after the crises [CGPS Working paper n. 60]. Bank for International Settlements, New York, USA. Retrieved from https://www.bis.org/publ/cgfs60.htm

Banco Central do Brasil. (2017). Relatório de economia bancária 2017. Retrieved from https://www.bcb.gov.br/pec/ depep/spread/REB_2017.pdf

Banco Central do Brasil. (2018). Relatório de economia bancária 2018. Retrieved from https://www.bcb.gov.br/ content/publicacoes/relatorioeconomiabancaria/ reb_2018.pdf

Berger, A., Klapper, L., \& Turk-Ariss, R. (2009). Bank competition and financial stability. Journal of Financial Services Research, 35(2), 99-118. https://doi.org/10.1007/ s10693-008-0050-7

Berger, A., Leora, K, \& Turk-Ariss, R. (2008). Bank competition and financial stability [Policy Research Working Paper $\mathrm{n}^{\circ}$ 4696]. World Bank, Washington, DC, USA. Retrieved from http://hdl.handle.net/10986/6794

Bikker, J., \& Haaf, K. (2002). Competition, concentration, and their relationship: An empirical analysis of the banking industry. Journal of Banking and Finance, 26(11), 2191-2214. https://doi.org/10.1016/S03784266(02)00205-4

Bikker, J. A., Shaffer, S., \& Spierdijk, L. (2009). Assessing competition with the panzar-rosse model: The role of scale, costs, and equilibrium [DNB Working Paper $\mathrm{n}^{\circ}$ 225]. De Nederlandsche Bank, Amsterdam, Netherlands. Retrieved from https://www.dnb.nl/ binaries/Assessing\%20 Competition\%20with\%20 the\%20Panzar-Rosse\%20Model_tcm46-224137.pdf

Boone, J. A. (2008). A new way to measure competition. The Economic Journal, 118(531), 1245-1261. https://doi. org/10.1111/j.1468-0297.2008.02168.x

Bulow, J. I., \& Shoven, J.B. (1978). The bankruptcy decision. The Bell Journal of Economics, 9(2), 437-456. https://doi. org/10.2307/3003592
Chamberlin, E. H. (1962). The theory of monopolistic competition. Cambridge, MA: Harvard University Press.

Choi, I. (2001). Unit root tests for panel data. Journal of International Money and Finance, 20(2), 249-272. https://doi.org/10.1016/S0261-5606(00)00048-6

Christensen, L. R., Jorgenson, D. W., \& Lau, L. J. (1973). Transcendental logarithmic production frontiers. The Review of Economics and Statistics, 55(1), 28-45. https://doi.org/10.2307/1927992

Claessens, S., \& Laeven, L. (2004). What drives bank competition? Some international evidence. Journal of Money, Credit \& Banking, 36(3), 563-583. https://doi.org/10.1353/ mcb.2004.0044

Conselho Monetário Nacional [CMN]. (2017). Resolução n. 4.553, de 30 de janeiro de 2017: Estabelece a segmentação do conjunto das instituições financeiras e demais instituições autorizadas a funcionar pelo Banco Central do Brasil para fins de aplicação proporcional da regulação prudencial. Diário Oficial da União. Retrieved from https://www.bcb.gov. $\mathrm{br} / \mathrm{pre} /$ normativos/busca/downloadNormativo. asp?arquivo=/Lists/Normativos/Attachments/50335/ Res_4553_v1_O.pdf

Conselho Monetário Nacional [CMN]. (2018). Resolução n. 4.656, de 26 de abril de 2018: Dispõe sobre a sociedade de crédito direto e a sociedade de empréstimo entre pessoas, disciplina a realização de operações de empréstimo e de financiamento entre pessoas por meio de plataforma eletrônica e estabelece os requisitos e os procedimentos para autorização para funcionamento, transferência de controle societário, reorganização societária e cancelamento da autorização dessas instituições. Diário Oficial da União. Retrieved from https://www.bcb.gov.br/pre/normativos/busca/ downloadNormativo.asp?arquivo=/Lists/Normativos/ Attachments/50579/Res_4656_v1_O.pdf

Dasgupta, P., \& Stiglitz, J. (1981). Entry innovation, exit: Towards a dynamic theory of industrial market structure. European Economic Review, 15(2), 137-158. https://doi.org/10.1016/0014-2921(81)90084-2

Delis, M. D., \& Tsionas. E.G. (2009). The joint estimation of bank-level market power and efficiency. Journal of Banking \& Finance, 33(10), 1842-1850. http://doi. org/10.1016/j.jbankfin.2009.04.006

Fisher, R.A. (1932). Statistical methods for research workers. Edinburgh: Oliver and Boyd.

Fungácová, Z., Shamshur, A., \& Weill, L. (2017). Does bank competition reduce cost of credit? Cross-country evidence from Europe. Journal of Banking and Finance, 83(C), 104-120. https://doi.org/10.1016/j. jbankfin.2017.06.014

Gilbert, A. (1984). Bank market structure and competition: A survey. Journal of Money, Credit, and Banking, 16(4), 617-644. https://doi.org/10.2307/1992096

Hankir, Y., Rauch, C., \& Umber, M. P. (2011). Bank M\&A: A market power story? Journal of Banking \& Finance, 35(9), p. 2341-2354. https://doi.org/10.1016/j. jbankfin.2011.01.030 
Hausman, J.A. (1978). Specification tests in econometrics. Econometrica, 46(6), 1251-1271. https://doi. org/10.2307/1913827

Lerner, A. (1934). The concept of monopoly and the measurement of monopoly power. The Review of Economic Studies, 1(3), 157-175. https://doi.org/10.2307/2967480

Maddala, G. S., \& Wu, S. A. (1999). Comparative study of unit root tests with panel data and a new simple test. Oxford Bulletin of Economics and Statistics, 61(S1), 631-652. https://doi.org/10.1111/1468-0084.0610s1631

Maghyereh, A. I., \& Awartani, B. (2014). Bank distress prediction: Empirical evidence from the gulf cooperation council countries. Research in International Business and Finance, 30(C), 126-147. https://doi.org/10.1016/j. ribaf.2013.07.001

Matutes, C., \& Vives, X. (1996). Competition for deposits, fragility, and insurance. Journal of Financial Intermediation, 5(2), 184-216. https://doi.org/10.1006/jfin.1996.0010

Matutes, C., \& Vives, X. (2000). Imperfect competition, risk taking, and regulation in banking. European Economic Review, 44(1), 1-34. https://doi.org/10.1016/S00142921(98)00057-9

Montes, C. P. (2014). The effect on competition of banking sector consolidation following the financial crisis of 2008. Journal of Banking \& Finance, 43(C), 124-136. https://doi.org/10.1016/j.jbankfin.2014.03.004

Ornelas, J. R. H., Silva, M. S da., \& Van Doornik, B. F. N. (2020). Informational switching costs, bank competition and the cost of finance [Working Paper Series $\mathrm{n}^{0}$ 512], Banco Central do Brasil, Brasília, DF, Brazil .Retrieved from https://www.bcb.gov.br/pec/wps/ingl/wps512. pdf

Panzar, J. C., \& Rosse, J. N. (1987). Testing for "monopoly" equilibrium. Journal of Industrial Economics, 35(4), 443-56. https://doi.org/10.2307/2098582

Pindyck, R. S., \& Rubinfeld, D.L. (2010). Microeconomia. São Paulo: Pearson Education do Brasil.

\section{Autores}

\section{Monique de Abreu Azevedo*}

Setor Bancário Sul, Quadra 3, Bloco B, Edifício Sede do Banco Central do Brasil, $7^{\circ}$ andar, Asa Sul, 70074-900, Brasília, DF, Brasil.

E-mail: monique.azevedo@bcb.gov.br

๑ https://orcid.org/0000-0003-4897-7227

\section{Ivan Ricardo Gartner}

Campus Universitário Darcy Ribeiro, s/n, Edifício FACE, Sala B2-B1-47/7, 70910-900, Brasília, DF, Brasil.

E-mail: irgartner@unb.br

๑ https://orcid.org/0000-0002-9780-1212

* Autor Correspondente
Silva, M. S. (2014). Avaliação do processo de concentraçãocompetição no setor bancário brasileiro [Trabalhos para discussão, $\mathrm{n}^{\circ}$ 377], Banco Central do Brasil, Brasília, DF, Brazil.

Shaffer, S., \& Srinivasan, S. (2002). Structure-pricing linkages among single-market banks, controlling for credit quality. Applied Economics Letters, 9(10), 653-656. https://doi.org/10.1080/13504850110115159

Shaffer, S., \& Thomas, L. (2007). A reassessment of market power among credit card banks. Applied Financial Economics, 17(9), 755-767. https://doi. org/10.1080/09603100600771042

Tabak, B. M., Gomes, M. R., \& Medeiros, Jr., M. (2015). The impact of market power at bank level in risk-taking: The brazilian case. International Review of Financial Analysis, 40(C), 154-165. https://doi.org/10.1016/j. irfa.2015.05.014

Turk-Ariss, R. (2010). On the implications of market power in banking: Evidence from developing countries. Journal of Banking \& Finance, 34(4), 765-775. https://doi. org/10.1016/j.jbankfin.2009.09.004

Tonooka, E. K., \& Koyama, S. M. (2003). Taxa de juros e concentração bancária no Brasil [Textos para discussão, n 62]. Banco Central do Brasil, Brasília, DF, Brasil.

VanHoose, D. (2010). The industrial organization of banking: Bank behavior, market structure and regulation. New York: Springer.

VanHoose, D. (1985). Bank and market structure and monetary control. Journal of Money, Credit, and Banking, 17(3), 298-311. https://doi.org/10.2307/1992626

Vries, C. G. de. (2005). The simple economics of bank fragility. Journal of Banking and Finance, 29(4), 803-825. https://doi.org/10.1016/j.jbankfin.2004.08.003

\section{Contribuições dos Autores}

$1^{\mathbf{a}}$ autora: Revisão de literatura; planejamento metodológico; coleta dos dados; aplicação do modelo; análise dos dados; interpretação dos resultados; redação do manuscrito.

$2^{\circ}$ autor: Revisão de literatura; planejamento metodológico; coleta dos dados; aplicação do modelo; análise dos dados; interpretação dos resultados; redação do manuscrito.

\section{Disponibilidade dos Dados}

Todos os dados e materiais foram disponibilizados publicamente por meio da plataforma Mendeley e podem ser acessados em:

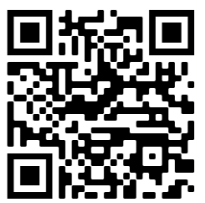

de Abreu Azevedo, Monique (2020), "Data for "Concentration and Competition in the Domestic Credit Market"”, Mendeley Data, v1 http://dx.doi.org/10.17632/c5kzfxbbb4.1 


\section{Financiamento}

A $1^{\text {a }}$ autora agradece ao apoio técnico e financeiro concedido pelo Banco Central do Brasil. As conclusões da pesquisa são de responsabilidade dos autores, não refletindo, portanto, a opinião desta Autarquia.

\section{Conflito de Interesses}

Os autores informaram que não há conflito de interesses.

\section{Direitos Autorais}

A RAC detém os direitos autorais deste conteúdo.

\section{Verificação de Plágio}

A RAC mantém a prática de submeter todos os documentos aprovados para publicação à verificação de plágio, mediante o emprego de ferramentas específicas, e.g.: iThenticate.

\section{Método de Revisão por Pares}

Este conteúdo foi avaliado utilizando o processo de revisão por pares duplo-cego (double-blind peer-review). A divulgação das informações dos pareceristas constantes na primeira página é feita somente após a conclusão do processo avaliativo, e com o consentimento voluntário dos respectivos pareceristas. 